\title{
Las redes de Movilidad Urbana Sostenible y la reactivación del Espacio Público: Alcosa
}

\author{
Sustainable urban mobility networks and the \\ reactivation of the public space: Alcosa
}

\author{
Esteban de Manuel Jerez,* Conso González Arriero* y Marta Donadei* \\ Fecha de recepción: 08-08-2016 - Fecha de aceptación: 18-10-2016 \\ Hábitat y Sociedad (ISSN 2173-125X), n. . 9, noviembre de 2016, pp. 97-131.
}

\begin{abstract}
Summary
There is a direct relationship between use of public space and mobility model. Facing the problems regarding the reactivation of public space at neighbourhood scale goes through a change of metropolitan mobility model in favor of the alliance between public transport and active mobility: cycling and pedestrian. In the framework of the Participatory Action Research (PAR) project "Barrios en Transición", carried out at the Sevillian neighbourhood of Parque Alcosa, we have made a diagnosis about the relationship between mobility model and public space occupancy. From the problems and neighboring claims found we have developed a proposal to reduce the dependency on private transport and reduce its occupation of public space, based on the alliance between an efficient public transport network and the improvement of the network and resources for cycling. Improving the efficiency of public transport network brings us to propose a basic network of Bus Rapid Transit for Seville. At neighbourhood scale we made a proposal to improve accessibility, pedestrian and cycling mobility and to stimulate the use of public space.
\end{abstract}

\section{Key words}

Public Space, sustainable mobility, Bus Rapid Transit, Neighborhoods, Participation, Transition Towns, Sevilla

\begin{abstract}
Resumen
Existe una relación directa entre uso del espacio público y modelo de movilidad. Afrontar los problemas de reactivación del espacio público a escala de barrio, pasa por cambiar el modelo de movilidad metropolitano en favor de la alianza entre transporte público y la movilidad activa: ciclista y peatonal. En el marco del proyecto de Investigación Acción Participativa (I. A. P.) Barrios en Transición, llevado a cabo en el barrio sevillano de Parque Alcosa, hemos trabajado un diagnóstico sobre la relación entre modelo de movilidad y ocupación del espacio público. A partir de los problemas y demandas vecinales encontradas hemos desarrollado una propuesta para reducir la dependencia del vehículo privado y reducir su ocupación de espacio público, sobre la base de la alianza entre una red de transporte público eficiente y la mejora de la red y las dotaciones para la bicicleta. La mejora de la eficiencia de la red de transporte público nos lleva proponer una red básica de Bus de Rápido Tránsito para Sevilla. A nivel de barrio realizamos una propuesta para mejorar accesibilidad, la movilidad peatonal y en bicicleta y para activar el uso del espacio público.
\end{abstract}

\section{Palabras clave}

Espacio Público, Movilidad Sostenible, Bus de Rápido Tránsito (B.R. T.), Barrios, Participación, Ciudades en Transición, Sevilla

* Grupo ADICI (HUM-810), ETSA Sevilla, correos: edemanuel@us.es, conso.arriero@gmail.com y mdonadei@us.es. 


\section{Planteamiento del problema}

El barrio de Alcosa, como todo el distrito Este, cumple una función eminentemente residencial. Esto provoca importantes flujos de tráfico diarios hacia las áreas productivas que colapsan las infraestructuras viarias. Infraestructuras que comunican al tiempo que fragmentan el territorio y provocan un "efecto isla" del barrio respecto a la ciudad. Por otra parte, es perceptible en el barrio la consecuente invasión del espacio público por el vehículo privado.

En el marco del Proyecto Barrios en Transición, que se plantea para impulsar el proceso de rehabilitación y transición a la sostenibilidad, fruto de la colaboración entre las entidades vecinales de Alcosa y el equipo del grupo de investigación ADICI de la Universidad de Sevilla, hemos trabajado con los vecinos en el diagnóstico de los problemas de relación barrio-ciudad, buscando alternativas para una movilidad más sostenible (de Manuel Jerez et al., 2012). Asimismo, hemos analizado los problemas derivados de un espacio público ocupado sustancialmente por el coche y que no ofrece oportunidades de interacción social.

Partiendo del diagnóstico, planteamos una estrategia de reorganización y reactivación del espacio público y de cambio del modelo de movilidad.

\section{Contexto: Alcosa una isla conectada}

El Parque Alcosa es un polígono de vivienda social situado al noreste de la ciudad, junto al aeropuerto, que se fue conformando en varias etapas a partir del año 1969 sobre una dehesa propiedad de la familia Gregorio Marañón. Surge al margen del planeamiento de la ciudad, como una isla urbana conectada a la carretera nacional IV, hoy autovía del Sur, entre las que existían paquetes de suelo rústico y suelo sin edificar. Alcosa nace vinculado al polígono La Algodonera, cuya actividad ha cesado, en el que trabajaba una parte significativa de sus vecinos.

El desarrollo posterior de la ciudad ha extendido la mancha urbana y creado nuevas infraestructuras de movilidad motorizada. El distrito Este, en el que ha quedado englobado Alcosa, es un sector conformado

Figura 1. Relación barrio-ciudad. Infraes tructuras viarias, barreras. Fuente: Alumnos de Taller 4.07 de Arquitectura Alba Castillo, María Fernández y Elena Espinosa. Prof. Irene Mendoza, Esteban de Manuel, Carlos Díaz-Recasens, Francisco Marquez, Marta Donadei.

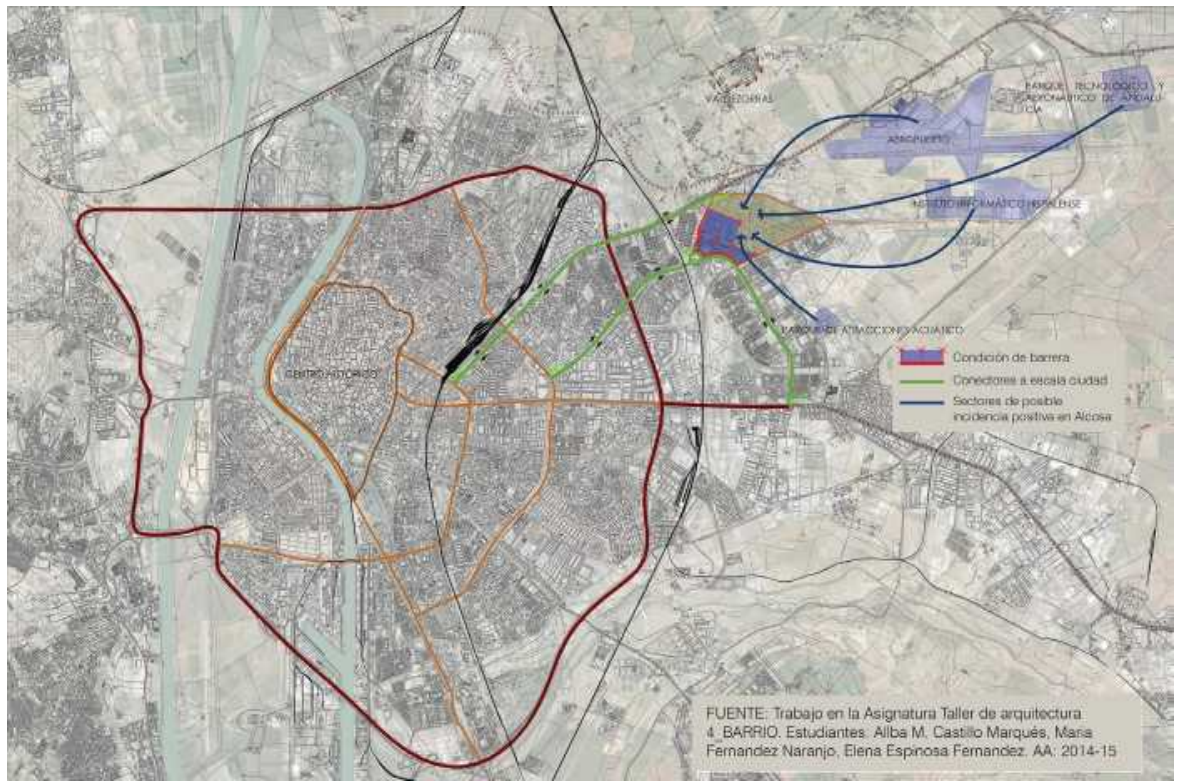




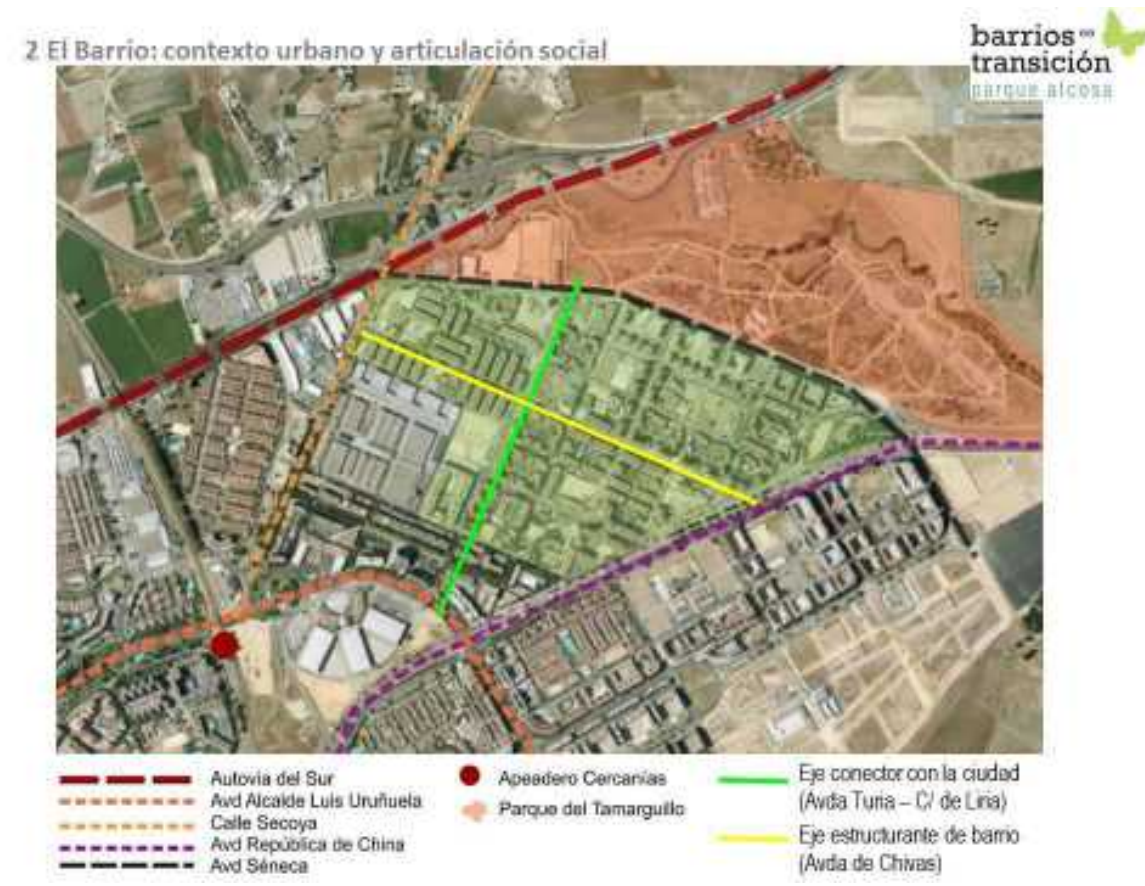

entre dos autovías, la radial A-4 que conecta Madrid con Cádiz y la transversal A-92 que vertebra Andalucía, y la circunvalación SE-30. La Av. de Alcalde Luis Uruñuela, de tres carriles por sentido vertebra el distrito, que cuenta con varios atractores de rango metropolitano: el parque metropolitano del Tamarguillo, el Palacio de Exposiciones y Congresos, dos centros comerciales y el Parque Tecnológico Aeronáutico de Andalucía (figura 1).

Alcosa es una especie de isla por el carácter de sus bordes (figura 2). Se encuentra delimitada al norte por el Parque del Tamarguillo, del que lo separa la Av. de Séneca, tras el cual se sitúa el aeropuerto, infraestructura de gran impacto en el barrio. Al sur se comunica, con dificultad, con la Avda. Alcalde Luis Uruñuela, por el carácter de borde que suponen las manzanas construidas entre el barrio y dicha avenida, de uso terciario. Al este el barrio se comunica también con dificultad con la Avenida República de China, de la que le separa la canalización del arroyo de Ranilla, sobre-elevado respecto al barrio. Y al oeste se encuentra delimitado por la calle Secoya, que tiene más carácter de carretera que de vía urbana. La superficie del barrio es de 93,14 ha que sumada a la del Parque del Tamarguillo (96 ha) y la Algodonera (12,54 ha) comprenden en total 201,68 ha.

Cuenta con 8113 viviendas y una población de 23000 habitantes. Está estructurado en torno a dos ejes principales y una red de calles paralelas a dichos ejes. Dichos ejes, girados casi $45^{\circ}$ respecto a los norte-sur, los componen la Avda. de Chiva, que atraviesa el barrio de izquierda a derecha, y Av. de Turia y su prolongación, la C/ Liria, que lo atraviesan de arriba abajo.

Esta situación periférica, del barrio y del distrito, colgada de grandes infraestructuras para el coche que se constituyen en barreras para la movilidad activa (peatón/bici) y el insuficiente desarrollo de la red de transporte público metropolitano, propician que el modelo de movilidad dominante en el barrio, particularmente en desplazamientos al trabajo, descanse en gran medida en el coche.
Figura 2. Viario principal en la relación barrio-ciudad. Fuente: Elaboración propia. 


\section{Fundamentación}

Existe una relación directa entre modelo de ciudad, movilidad y ocupación del espacio público. La aplicación de los principios de segregación funcional del urbanismo moderno al diseño de las ciudades da origen a áreas residenciales, productivas, de servicios y ocio, comunicadas por grandes redes de movilidad para el vehículo y el transporte privados (Borja, Jordi ; Muxí, 2003; José, 1998; Mollinedo, 2006; Verdaguer, 2000). Este proceso se ha visto acelerado en las últimas décadas en Sevilla, como en muchas otras grandes ciudades, con la creación del área metropolitana. La consecuencia de este modelo es la multiplicación de los desplazamientos motorizados obligados y la creciente preeminencia de los modos privados sobre los públicos.

Ello conlleva medidas de diseño y ejecución de infraestructuras y reparto de espacio público que privilegian al coche sobre la movilidad en transporte público y la activa, así como la creciente ocupación por parte del coche de la mayor parte del espacio público (Calvo Salazar, 2013), produciendo lo que Jaime Lerner denomina colesterol urbano (Lerner, 2003).

El reto de reducir la movilidad motorizada privada requiere medidas de reestructuración urbana, haciendo ciudad compleja donde solo hay agregación de urbanizaciones, y sinergia entre las redes de transporte público, bicicleta y caminos peatonales.

La creación de proximidad es el primer principio de la movilidad sostenible, porque los desplazamientos próximos pueden realizarse con movilidad activa (caminando o en bicicleta). Pero no basta con que las distancias sean cortas, es necesario que los recorridos peatonales y en bicicleta sean seguros y accesibles, sin barreras. Ello implica una reestructuración del espacio público, hoy pensado fundamentalmente para el vehículo, para generar redes continuas y seguras de movilidad peatonal y en bicicleta, ganando espacio al coche (Carles Llop; Salvador Rueda, 2011; Verdaguer, 2000).

\section{Las tres redes de movilidad sostenible}

El segundo principio de la movilidad sostenible es el establecimiento de sinergias y alianzas entre movilidad activa y transporte público. Para ello las ciudades se están dotando de tres redes continuas: la de transporte público, la de bicicletas y la peatonal, cada una de ellas con sus infraestructuras de apoyo y de intermodalidad.

Las tres redes de movilidad sostenible tienen que cumplir algunos criterios comunes para constituir una alternativa atractiva al automóvil. Tienen que ser eficaces, continuas, amables y multifuncionales, además de interconectarse adecuadamente entre sí. Eficaces en tiempo de desplazamiento, sin barreras ni discontinuidades, debe ser agradable transitar por ellas y deben ser útiles tanto para desplazamientos por motivo de trabajo como de ocio (Calvo Salazar, 2013; Corral Sáez, 2006).

\section{Redes de transporte público eficientes}

La red de transporte público metropolitana de Sevilla está en construcción. La componen la línea 1 de metro, las líneas de cercanías y las líneas de autobuses. Se ha avanzado en gestión integrando todas las líneas concesionadas a través del consorcio, con la implantación de la 
tarjeta de transporte, y se han dado los primeros pasos en intermodalidad con la bicicleta, al menos en la ciudad de Sevilla. Aun así, la red actual de transporte metropolitano está lejos de articular el área de forma eficaz. La expansión de la ciudad metropolitana ha incrementado en casi un $50 \%$ la movilidad mecanizada haciéndola descansar fundamentalmente en el automóvil. Si en 1983 se producía 1,08 desplazamientos mecanizados por habitante, en 2004 eran 1,56 y en 2007 de 2,33. El porcentaje de participación entre transporte público y privado se invirtió en el periodo. En 1983 el 43\% de los desplazamientos se producían en transporte público, frente al $46 \%$ en vehículo privado. En 2004 el porcentaje de desplazamientos en transporte público bajó al 20,6\% y el de vehículo privado se disparó al 70\% (Junta de Andalucía, 2015).

La construcción de la ciudad metropolitana ha supuesto un incremento de la movilidad mecanizada con pérdida de peso del transporte público en favor del vehículo privado. El desarrollo de la red de metro en Sevilla está paralizado. No es previsible que pueda completarse la red en un futuro razonable y resolver el problema de la movilidad sostenible a nivel metropolitano pasa por buscar alternativas mejorando la eficiencia de la red de transporte público de superficie. El arquitecto Jaime Lerner, director del Plan Maestro de Curitiba, se planteó el problema de deconstruir el metro subterráneo para reconstruirlo en superficie. De este modo surgió el conocido como Bus de Rápido Tránsito (B. R. T.) o metrobús. La aplicación exitosa del modelo ha provocado su rápida expansión. Este sistema demuestra que es posible conseguir resultados comparables a los del metro subterráneo en cuanto a alta capacidad de mover viajeros, velocidad comercial y frecuencia con una inversión económica al menos diez veces menor y una incomparable velocidad de implantación. Los principios bajo los que opera el modelo son los siguientes:

- Circulación de los vehículos por una plataforma reservada, de uso exclusivo, que transcurre por el centro de la calzada para evitar conflictos con los vehículos que desean estacionar o girar a la derecha.

- Prioridad semafórica en los cruces para evitar paradas.

- Estaciones a nivel de los vehículos para garantizar la accesibilidad universal.

- Picado de los billetes en las estaciones y apertura simultánea de todas las puertas.

- Vehículos de alta capacidad, biarticulados (capacidad de entre 80-120 pasajeros).

- Frecuencia de paso en horas punta de 4 min.

A estos puntos empieza a añadirse como un componente más del modelo la electrificación de los vehículos. Y esto por dos razones: La primera para reducir las emisiones de CO2 a la atmósfera y mejorar la calidad del aire y la segunda porque el cambio de modelo energético está empujando a la movilidad eléctrica basada en producción 100\% renovable. La red de B.R.T. se alimenta con la red de autobuses convencionales y tiene una gran potencialidad de conexión con la de bicicletas como demuestra el caso de la ciudad china de Lanzhou, en el que el sistema se alimenta con una red de bicicleta pública compartida. Este sistema estimamos que tiene un gran potencial en la Sevilla metropolitana, donde ya contamos con sistema de bicicleta pública. 


\section{Red de bicicletas}

El segundo elemento es la red de bicicletas, de rápido y exitoso desarrollo en la ciudad de Sevilla. Las claves del éxito han sido la continuidad de la red, las infraestructuras de apoyo, básicamente aparcamientos seguros, y el establecimiento de Sevici como sistema de bicicleta pública (Marqués, 2011). Pero es preciso dar un nuevo impulso a la red de la ciudad. Esto implica extender una red de aparcamientos seguros próximos a los hogares, especialmente en barrios residenciales que carecen de espacio en las zonas comunes de las viviendas colectivas para disponerlos. Y complementariamente en destino, particularmente en los lugares de trabajo y estudio, en los edificios de equipamientos y servicios públicos y en las estaciones de transporte público para favorecer la intermodalidad. Las redes de bicicletas en zonas de tráfico pacificado (zonas 20 y zonas 30) no precisan estar separadas, pueden compartir la calzada con el vehículo motorizado. Así la reorganización de la red viaria de la ciudad, diferenciando vías estructurantes con velocidad de $50 \mathrm{~km} / \mathrm{h}$ y limitando la velocidad en el resto, extendiendo la red viaria con prioridad peatonal y para la bicicleta, crea fácilmente las condiciones para el desarrollo de una red continua en la ciudad que solo precisa complementarse con carriles bici segregados cuando tengan necesariamente que transcurrir por el viario estructurante de la ciudad.

El Plan Andaluz de la bicicleta prevé la extensión de la red a nivel metropolitano. La intermodalidad transporte público-bicicleta, a partir de la construcción de una red de carriles bici y aparcamientos seguros, permitiría alimentar la red de transporte público con bajo coste en áreas de baja densidad, al incrementar el radio de acción servido por una parada de transporte público. Si para un peatón este radio de acción se fija en $300 \mathrm{~m}$, para una bicicleta esta distancia es de $3 \mathrm{~km}$. El área cubierta por una parada bien conectada es para la bicicleta cien veces superior. Partiendo de estas premisas, el equipo de investigación dirigido por el profesor Ricardo Marques Sillero ha analizado cuál sería el radio de influencia de las paradas que configuran la actual red de transporte público y ha demostrado que con una buena red de carriles bici y aparcamientos seguro en las paradas, permitiría cubrir la totalidad del área metropolitana. La bici podría jugar así un papel de enlace con las paradas tanto en origen como en destino (Hérnandez Herrador et al., 2014).

\section{Redes peatonales}

El tercer elemento es el de la movilidad peatonal, el más directamente relacionado con la reconfiguración y revitalización del espacio público. En La Ciudad Peatonal Rolf Monheim ya planteó las calles y áreas de coexistencia entre peatón y automóvil en las que este entraría con una velocidad adecuada a la prioridad peatonal (Peters, 1979). A nivel de barrio, en Alcosa vamos analizar los lugares con vocación de convertirse en centro de barrio y las medidas de reconfiguración del espacio público que harían posible el desarrollo de itinerarios peatonales seguros y continuos.

El impulso de la movilidad sostenible descansa sobre dos pilares: el desarrollo de las tres redes y su interconexión amable es la primera. Es condición necesaria. Pero es necesario contar con la participación ciudadana ya que en última instancia es esta la que tiene que cambiar sus hábitos de movilidad. 


\section{La reorganización del espacio público y la movilidad} aplicando el concepto de supermanzanas

Una reestructuración completa del espacio público basado en los principios de la ciudad peatonal y pensado para favorecer las tres redes de movilidad sostenible es la que propone Salvador Rueda, de la Agencia de Ecología Urbana de Barcelona, con su idea de articular la ciudad con supermanzanas. Idea concebida inicialmente para el ensanche de Barcelona, la supermanzana es una agrupación de tres por tres manzanas que dan un cuadrado, de eje a eje de calzada, de $400 \times 400 \mathrm{~m}$. La superposición de esta estructura sobre la estructura viaria de la ciudad da lugar a una red de viario estructurante, de tránsito $(50 \mathrm{~km} / \mathrm{h})$, que articula la ciudad, y una red interior a las supermanzanas con prioridad para el peatón y la bicicleta. El interior de las supermanzanas puede reurbanizarse con una plataforma única compartida de acceso restringido para los vehículos motorizados (fig. 3).

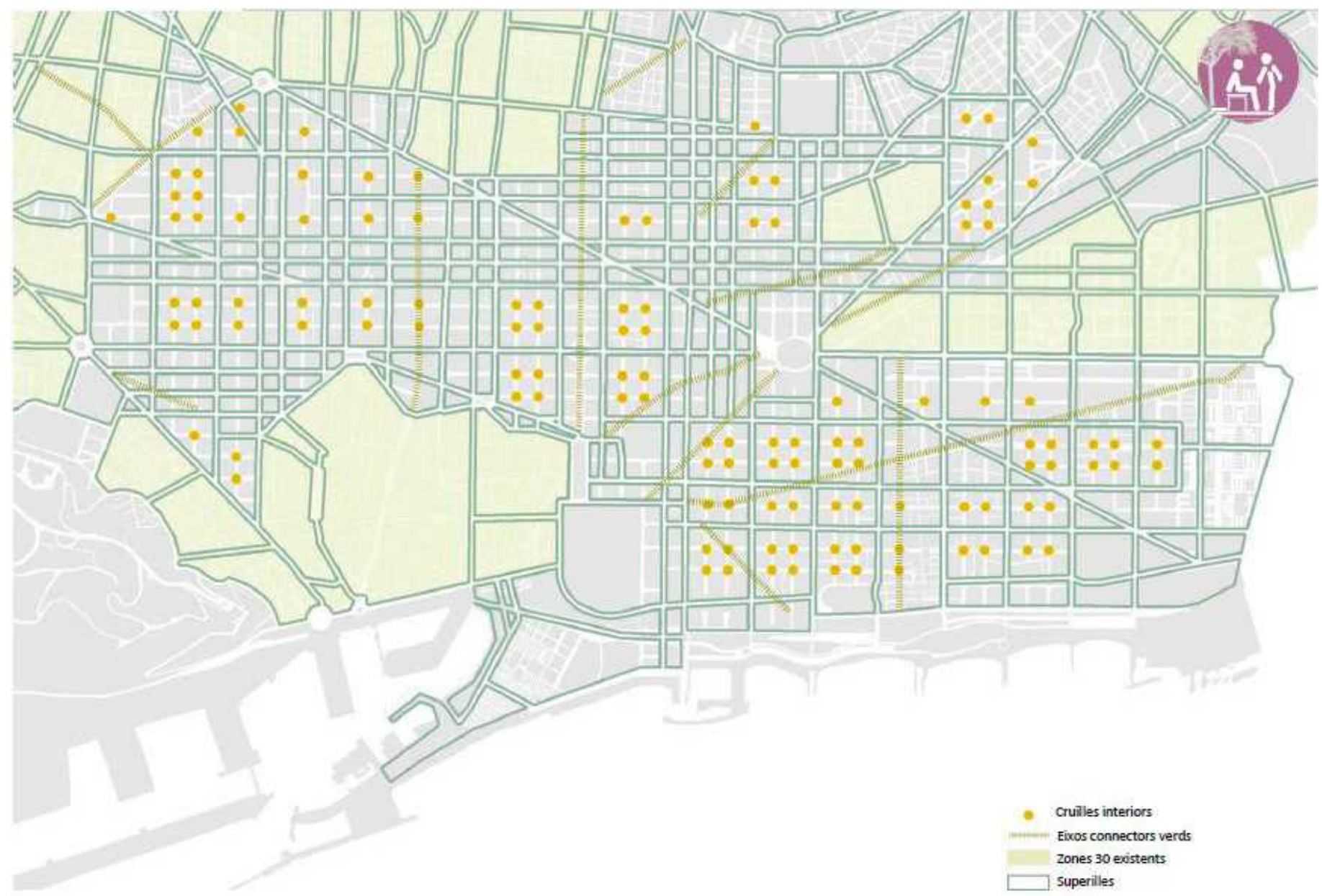

120 cruilles potencials

23 ha. aprox.

La aplicación del modelo a Barcelona ha permitido la reestructuración de la red de transporte público eficiente (figura 4) (Rueda \& Soler Trillo, 2004). De este modo, se garantiza que haya una parada de la red a una distancia máxima de cinco minutos del corazón interior de la manzana. Con un sistema básico de líneas horizontales y verticales se comunican dos puntos cualesquiera de la ciudad mediante un único transbordo. El modo de implantación es importante. Es preciso
Figura 3. Reorganización de la ciudad de Barcelona en supermanzanas. Fuente: Agencia de Ecología Urbana de Barcelona (Agencia de Ecología Urbana de Barcelona, 2015). 


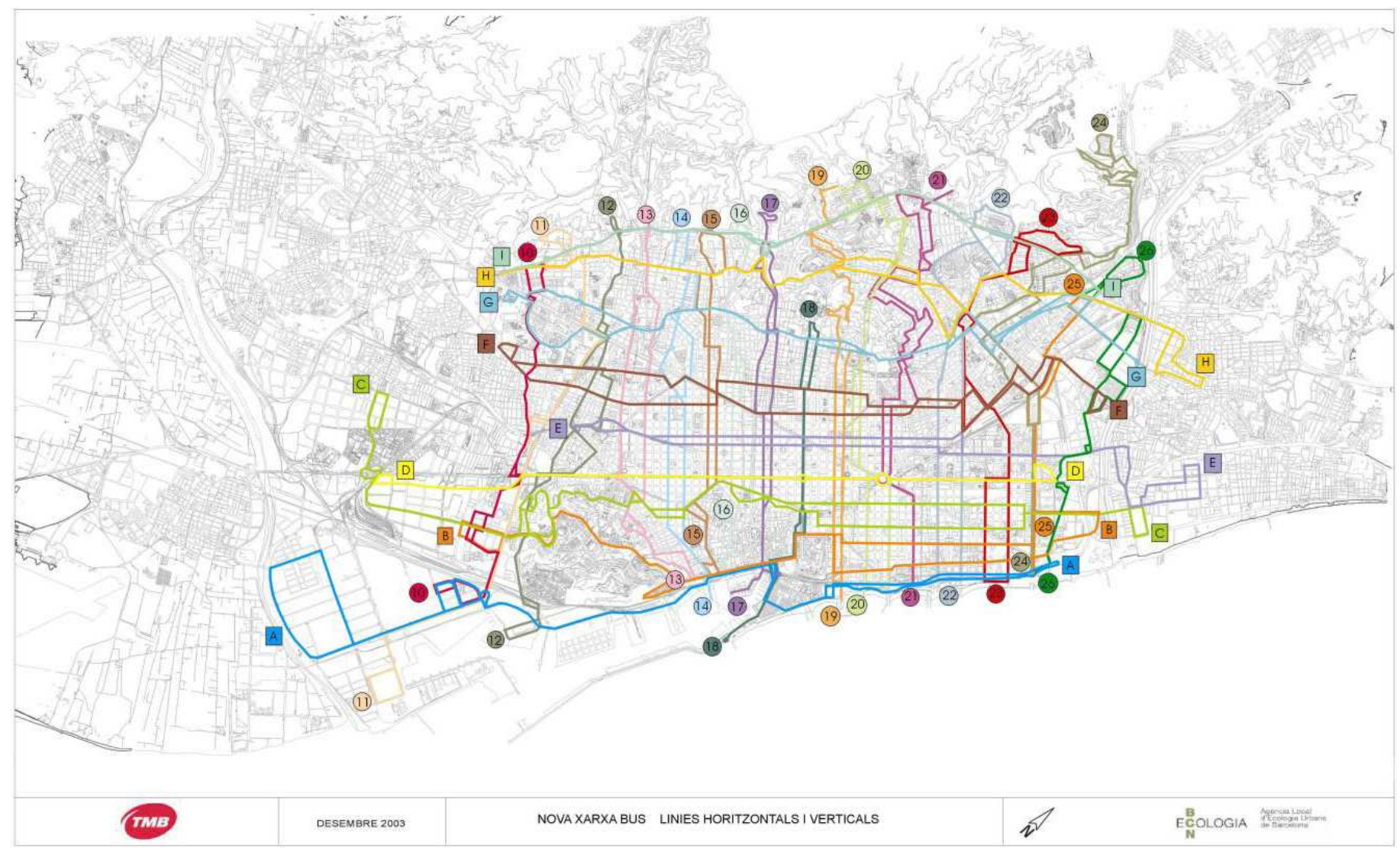

Figura 4. Diseño de la red de autobuses de Barcelona. Fuente: Agencia de Ecología Urbana de Barcelona, 2004.
Figura 5. Aplicación a Vitoria de la organización del espacio público en supermanzanas. Fuente: Agencia de Ecología Urbana de Barcelona, 2007. que desde el primer momento se cree una red, que progresivamente se vaya ampliando, y que permita conexiones entre las líneas. Barcelona está implantando este sistema a razón de tres líneas por año.

Este concepto ha sido aplicado en ciudades cuya estructura dista de la del ensanche barcelonés. Es el caso de Vitoria, cuyo plan de movilidad sostenible descansa en una reestructuración del espacio público (Agencia de Ecología Urbana de Barcelona, 2007). El esquema de la red viaria de esta ciudad es de tela de araña. La modificación introducida en el viario de la ciudad al aplicar el concepto de organización en supermanzanas define una red viaria con más pregnancia que la preexistente. $\mathrm{Al}$ dar prioridad peatonal al espacio interior de las supermanzanas se logra incrementar el espacio de prioridad peatonal del 9 al 57\% (fig. 5).

\section{(A) Red bàsica de vehículo de paso}
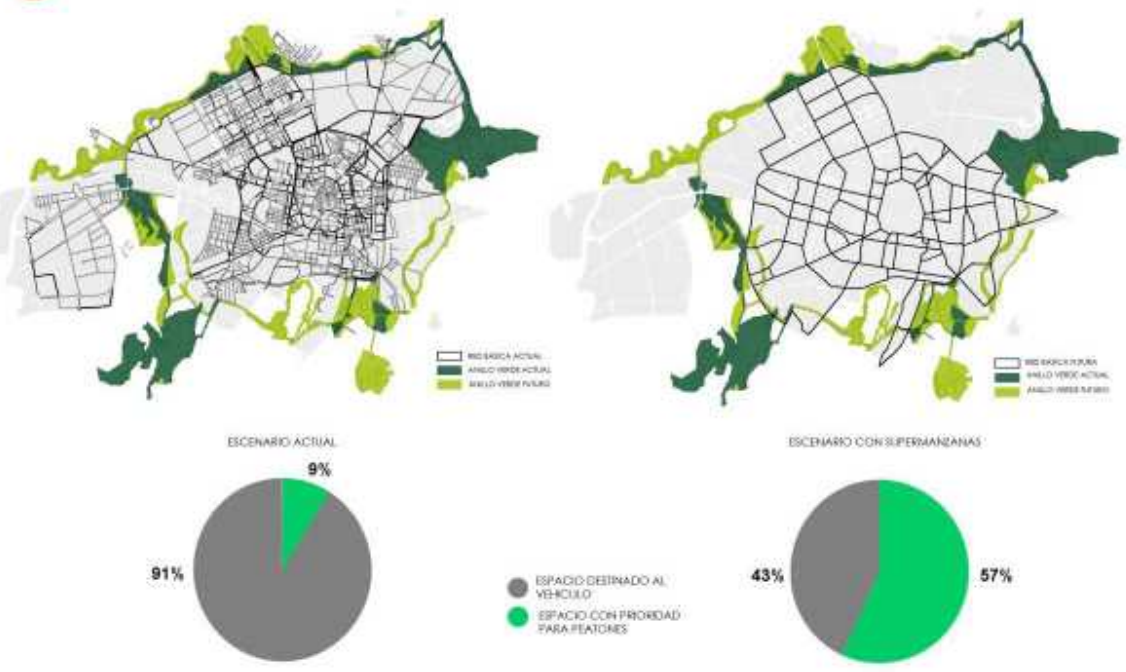
Ecobarrios como Vauban en Friburgo han aplicado los principios de la ciudad peatonal mediante la combinación de una buena conexión urbana con transporte público y medidas de restricción del acceso de vehículos de no residentes. El barrio cuenta con edificios de aparcamientos en altura. Las escasas plazas de aparcamiento en superficie están asignadas a residentes o trabajadores del barrio (las plazas tienen la matrícula del vehículo asociado). Hay pocas calles interiores a las que puede acceder el automóvil y siempre con prioridad peatonal. Y el diseño del espacio público es un híbrido entre barrio y parque público. Es un entorno completamente amable donde los niños y niñas pueden andar y jugar seguros en la calle. El reto al que nos enfrentamos en Alcosa es el de realizar una transición desde un trazado urbano pensado y dominado por el coche hacia un trazado urbano pensado y activado por los caminantes, en el que la frontera entre parque y ciudad se difumine (United Cities and Local Governments, 2010).

\section{Diseño de la investigación y metodología empleada}

La investigación acción participativa llevada a cabo en el marco del proyecto Barrios en Transición ha procurado el encuentro entre los saberes técnicos expertos y los vecinales (Fig.6). Estos últimos conocen problemas y fortalezas de primera mano e incluso proponen soluciones. Al mismo tiempo esperan una opinión técnica fundamentada sobre cómo sus problemas y necesidades podrían encontrar solución (López Medina, 2010).
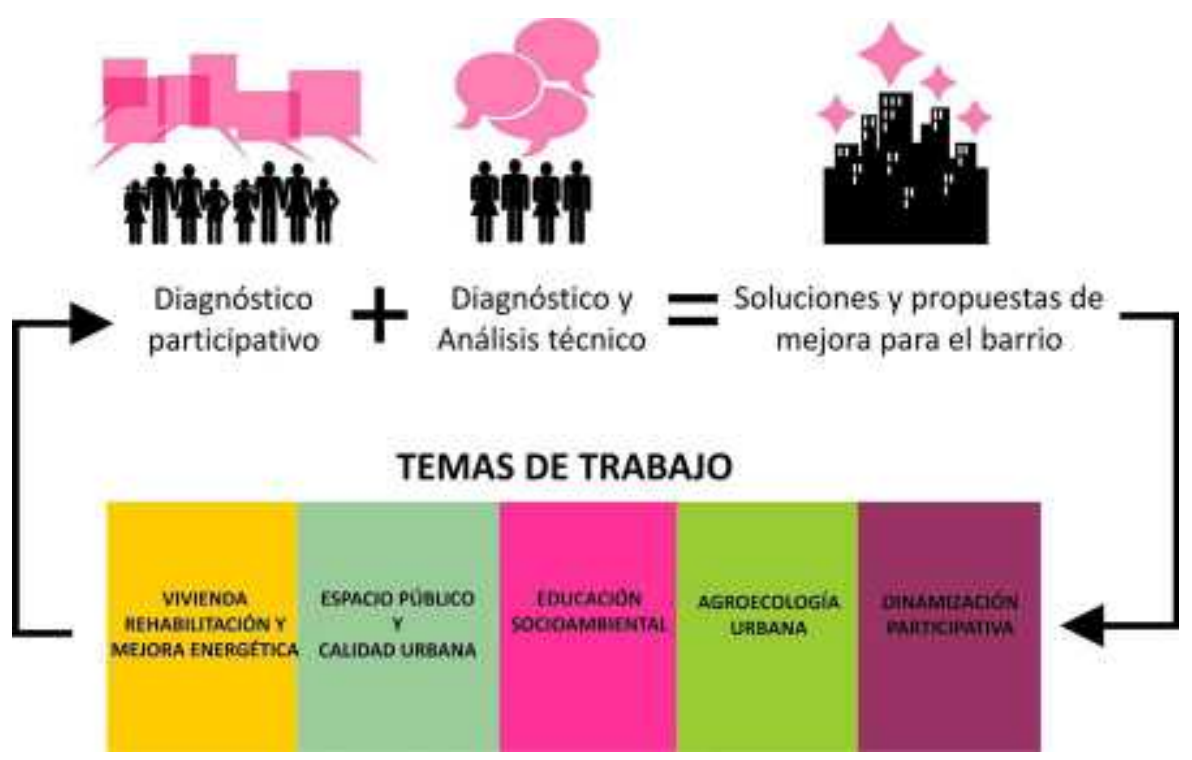

Para el diagnostico participado hemos empleado diferentes metodologías, tanto cuantitativas como cualitativas. Partimos de unos talleres técnico-vecinales de diagnóstico y elaboración de propuestas en los que aplicamos la metodología de Plan Base-Plan Barrio (Morales, 2014). Estos talleres nos permitieron identificar problemas, priorizarlos, organizarlos en áreas de trabajo y apuntar líneas estratégicas a seguir desarrollando. El área de espacio público y movilidad la continuamos trabajando en dos jornadas. El Park(ing)Day, en colaboración con la comunidad escolar del Colegio Público Lope de Rueda, de la que extrajimos un diagnóstico y propuestas sobre espacio público elaborados
Figura 6. Esquema de la metodología de diagnóstico y elaboración de propuestas participativa. Fuente: Elaboración propia. 
Figura 7. Actores del barrio involucrados en el diagnóstico de movilidad y espacio público. Fuente: elaboración propia.

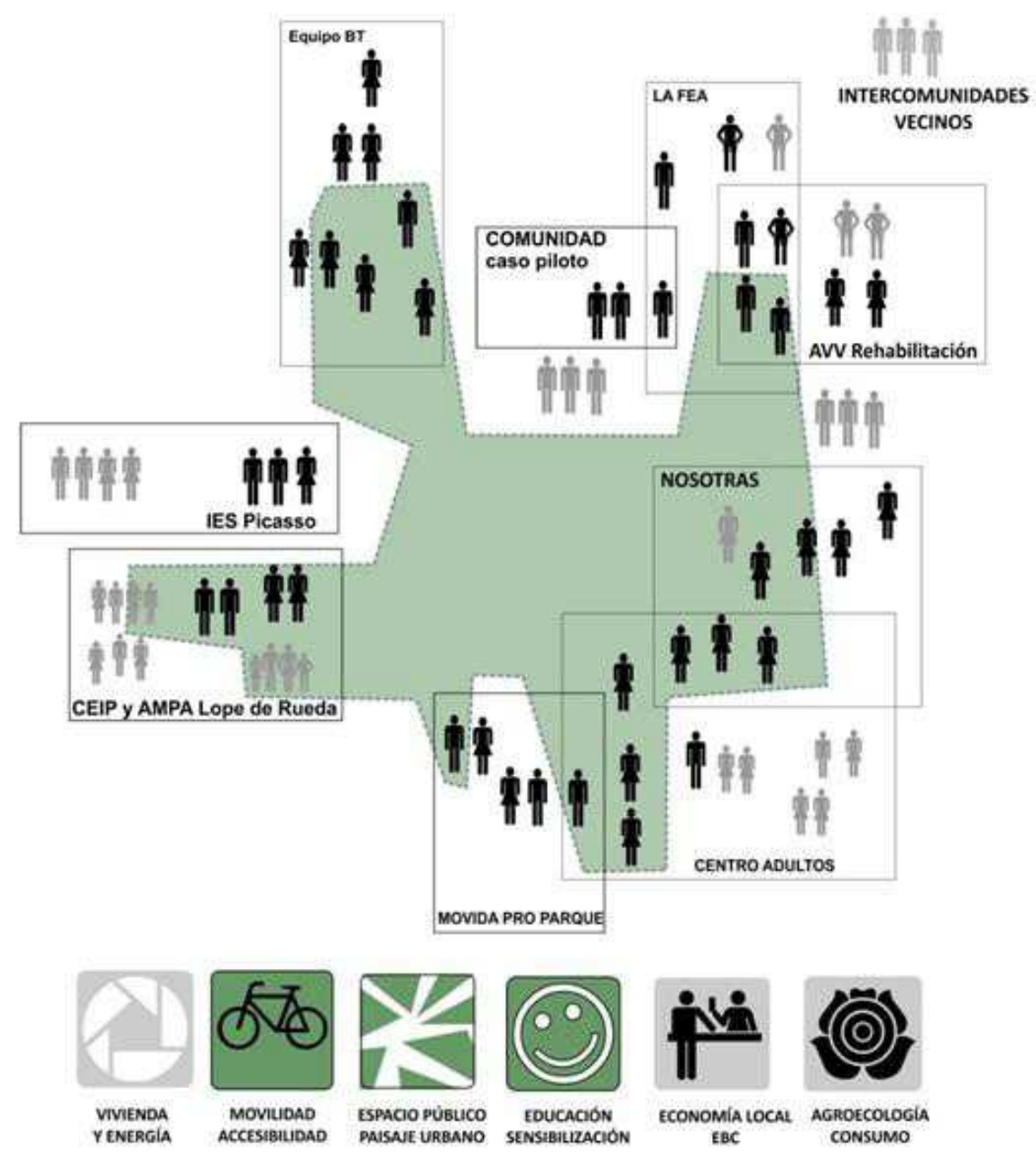

por los niños y niñas. Y Alcosa Se Mueve, en colaboración con el Centro de Adultos del barrio, para elaborar un diagnóstico sobre problemas de accesibilidad y movilidad a nivel de barrio y donde planteamos una estrategia para mejorar la relación barrio ciudad mediante la alianza entre redes eficientes de transporte público y bicicleta. Los talleres participativos se han complementado con grupos de discusión con expertos.

\section{Diagnóstico del espacio público y la movilidad en Alcosa}

Hemos utilizado cuatro criterios interrelacionados entre sí, para abordar tanto el diagnóstico como las propuestas de intervención. En un primer acercamiento a las mejoras del espacio público y la calidad urbana, el análisis se realizará en base a la movilidad, la actividad, el paisaje urbano y la identidad.

La movilidad la hemos analizado desde dos escalas, la suprabarrial, donde las vecinas y vecinos necesitan desplazarse fuera del barrio, por otro lado la escala de barrio, donde se realizan la mayoría de tareas cotidianas (Ciocoletto y Punt6 Collectiu, 2014). La actividad se refiere a la diversidad de usos y actividades correspondientes a distintos grupos de edad y colectivos. Desde criterios de paisaje urbano, estudiamos las condiciones físicas apropiadas del entorno urbano, de las plazas, calles y espacios libres del barrio. Por último desde la Identidad analizamos las características y condiciones que hacen a los espacios del barrio 
puntos de referencia, que hacen que se perciben como espacios representativos donde las personas desarrollan un sentido simbólico y de pertenencia.

\section{Movilidad: Relación barrio ciudad}

Alcosa es un barrio que depende funcionalmente de la ciudad central y el área metropolitana para acceder a los puestos de trabajo, la realización de estudios superiores, la asistencia sanitaria hospitalaria y a los grandes equipamientos deportivos, de ocio y de transporte. Las líneas de transporte público que comunican el barrio carecen de la capacidad, velocidad y frecuencia suficientes para ser competitivas con el automóvil. Esto provoca una gran dependencia del coche que genera atascos cotidianos en las horas puntas coincidentes con la entrada y salida del trabajo.

\section{Redes de transporte público}

Las dos líneas que atraviesan el barrio (28 y B4) lo conectan con el centro pero la frecuencia de paso y la velocidad comercial no son adecuadas para que supongan un sustituto de los desplazamientos en coche. La conexión con la zona norte y sur para acceder a servicios básicos como el sanitario (hospital Macarena y Virgen del Rocío) obliga a los vecinos y vecinas a realizar muchos transbordos que incrementa aún más sus tiempos de desplazamiento (Fig. 8).

Las dos líneas de autobús que entran en el barrio tienen varias paradas que barren casi la totalidad de su superficie. Existen un total de 20 paradas dentro del barrio y podríamos decir que es una red de proximidad, ${ }^{1}$ el inconveniente es la frecuencia. El tiempo medio de espera de la línea B4 ronda los 20 minutos, en consecuencia el transporte en autobús pierde eficacia y atractivo para los usuarios del barrio.

El tren de cercanías podría suponer un recurso importante para la movilidad hacia el norte y el sur de la ciudad. Sin embargo, el precio del billete, el hecho de que la línea circular ya no circule en ambos sentidos, y la poca frecuencia de la línea B4 que conecta Alcosa con la estación de Palacio de Congresos hacen que sea un medio infrautilizado.

\section{La organización del espacio público en Alcosa y los recorridos peatonales}

El barrio histórico de Alcosa se realiza en dos etapas con una configuración de los edificios y el espacio público muy diferente. La primera fase, construida en la primera mitad de los setenta, ubicada a la izquierda de la calle Liria, está organizada en bloques longitudinales agrupados de dos en dos, conocidos en el barrio como "Los Martillos". Tienen una calle de acceso central, tanto para vehículos como para la entrada a las viviendas. El espacio libre peatonal discurre paralelo a los bloques lineales, se trata de una franja blanda con abundante vegeta-

Figura 8. Conexiones mediante transporte público de Alcosa. Fuente: estudiandes María Hormigo Gamero, Maria del Mar Silvente Bretones, Matías Yunes Leites. Asignatura Hábitat y Desarrollo (2012131, profesor Esteban de Manuel.
1 Según el Plan Especial de Indicadores de Sostenibilidad Ambiental de la Actividad Urbanística de Sevilla se considera una red de transporte público accesible cuando los desplazamientos a pie hasta la parada más próxima no superan los cinco minutos (ámbito de influencia medio de 300 metros). 


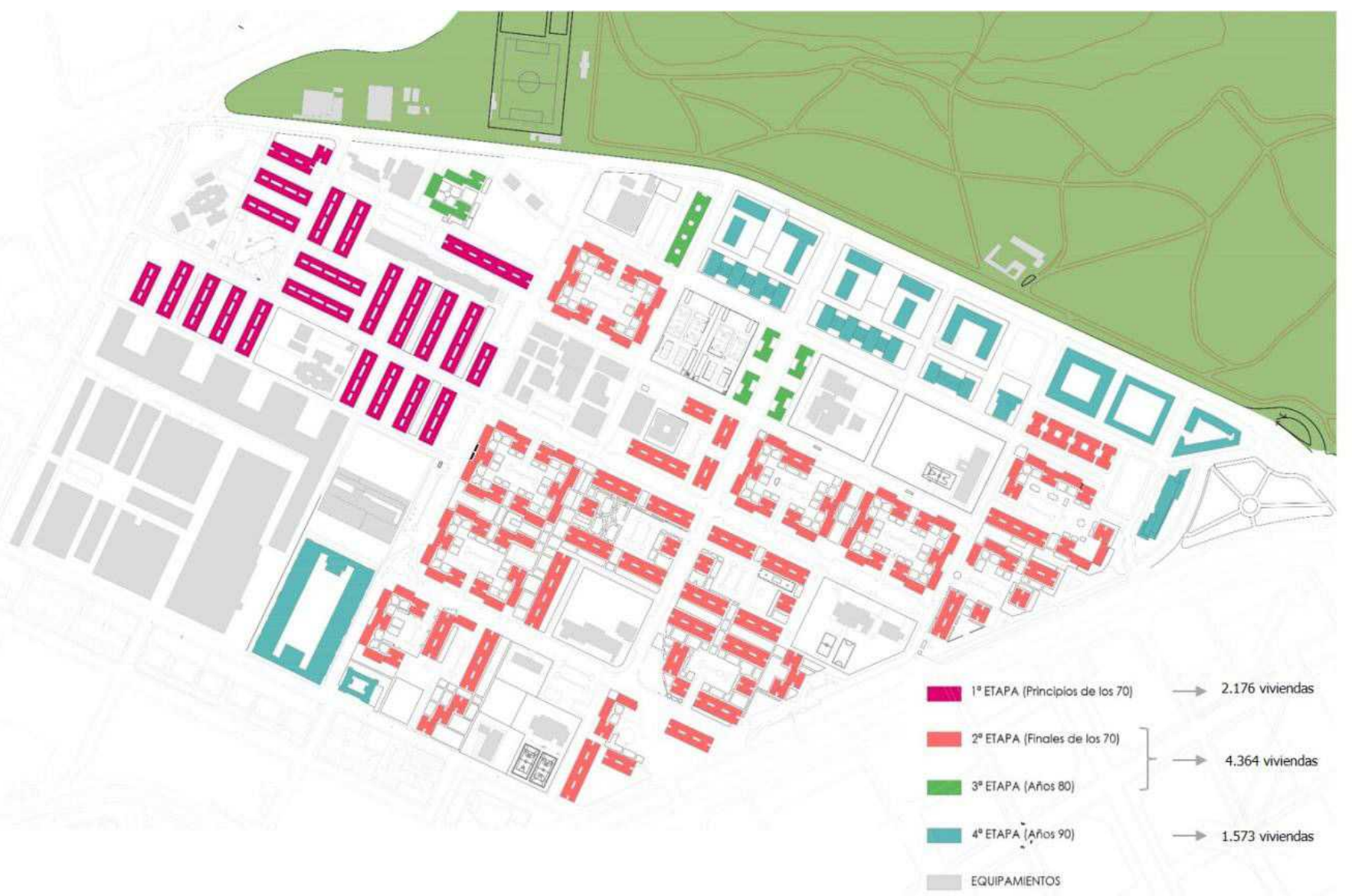

Figura 9. Evolución constructiva del barrio. Fuente: Trabajo de la asignatura Taller de Arquitectura 4.07 Barrios, del curso 2014-2015. Alumnos: I. Gómez, A. Ricarte, J. Torrejón. Profesores: Irene Mendoza, Esteban de Manuel Jerez, Marta Donadei, Francisco Márquez, y Carlos Díaz-Recasens.

Figura 10. Espacio público entre bloques lineales "Los Martillos". Fuente: Elaboración propia. ción de mediano y en ocasiones gran porte, con una acera estrecha a cada lado, a este espacio solo dan ventanas y balcones, no hay ningún acceso a las viviendas desde aquí. Estos jardines presentan una gran variedad de plantas y arbolado, con un buen mantenimiento y limpieza en algunas zonas pero abandonados en otras, no existe mobiliario urbano en ningún caso y la mayoría están cerrados con vallas. Los que quedan abiertos se utilizan como lugar de paso aunque la estrecha acera no deja espacio para dos peatones (figura 10).
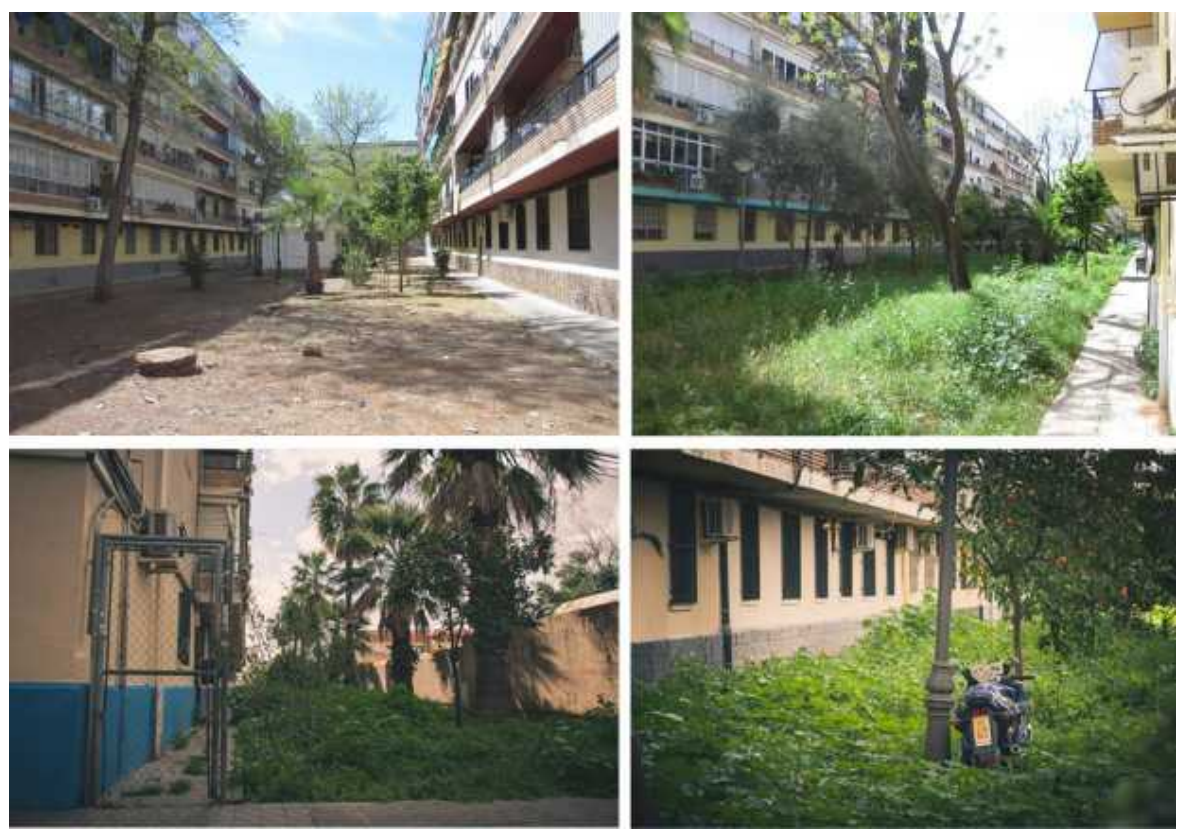
A la derecha de la calle Liria se construyó la segunda fase, a finales de los setenta, conocida como "las plazas", por la disposición de los bloques que se resuelve en torno a una plaza semicerrada con un espacio central. El corazón de la plaza está dedicado al aparcamiento de vehículos y esta isla, a su vez, está rodeada de espacios blandos con vegetación, cerrados con vallas que dejan un espacio angosto para circular. En las esquinas de la plaza hay espacios pavimentados con elementos de mobiliario urbano, este es el lugar que se usa como plaza, donde es posible la estancia, aunque es el de menor superficie.
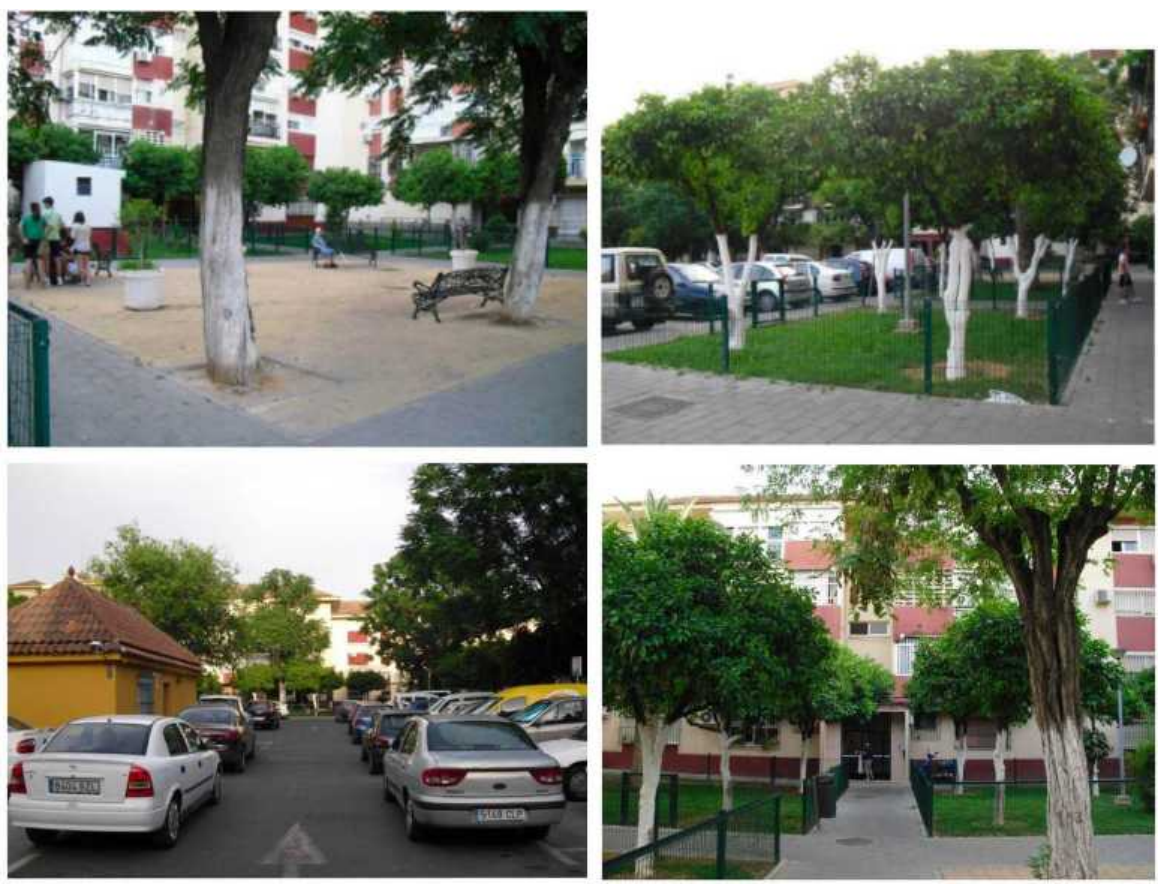

Figura 11. Espacio Público en el interior de "Las Plazas". Fuente: Elaboración propia.
El barrio está bien equipado. Cuenta con varias instalaciones deportivas públicas, con una Biblioteca Pública situada en el Centro Cívico, dos Institutos (Pablo Picasso y María Moliner) y 5 colegios (Benjumea Burín, Arrayanes, Lope de Rueda, Manuel Cortina, Lope de Vega), un centro de formación profesional concertado (ADA) y el Centro de Adultos. Existe también un centro de salud y una residencia de mayores privada, además de una parroquia (Nuestra Señora de los Desamparados) y la Iglesia Beata Ana María de Javohuey y San José de Cluny. El comercio se ubica inicialmente en torno a un "zoco" en el corazón del barrio y una calle comercial (fig.12).

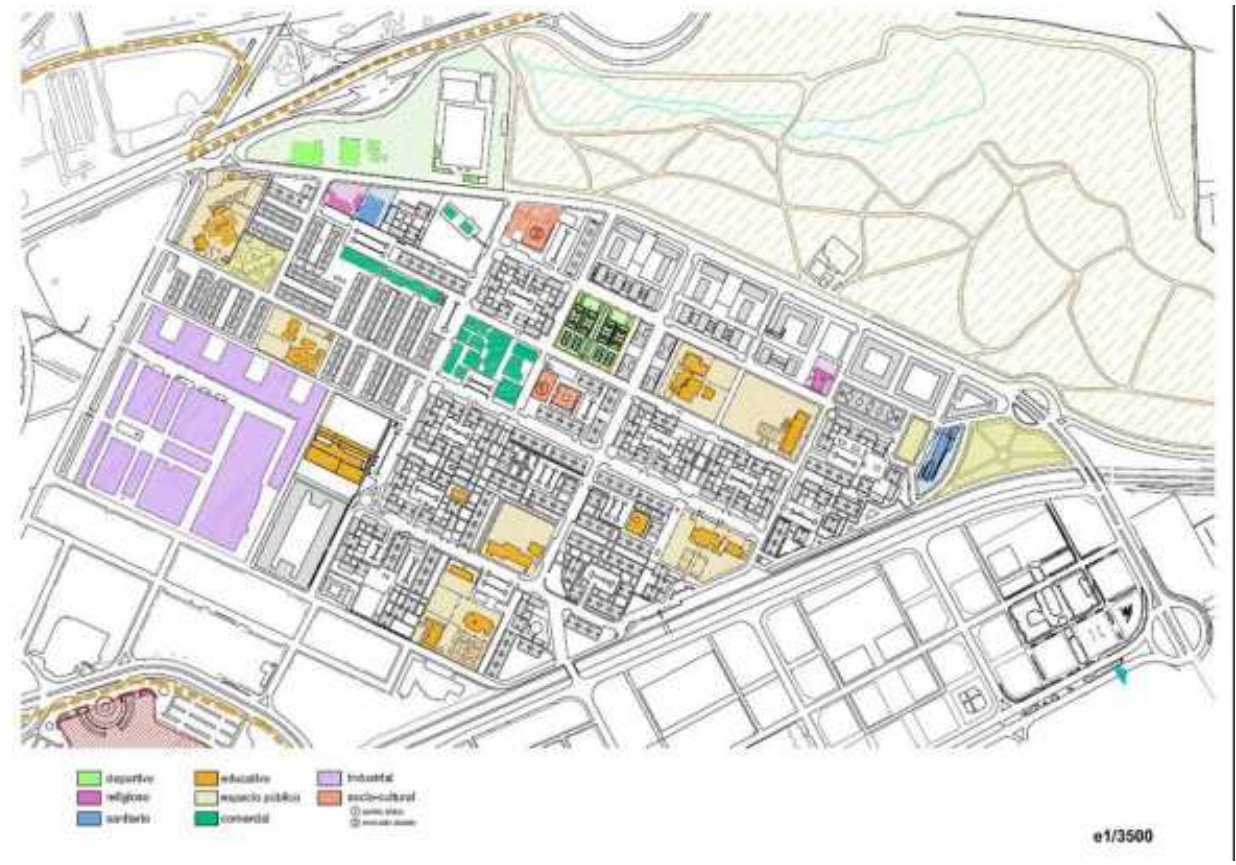

Figura 12: Dotaciones y equipamientos en Alcosa. Fuente: Conso González Arriero. 
En relación a la movilidad infantil, en trabajos realizados con los alumnos y alumnas del CEIP Lope de Rueda, comprobamos que muchos alumnos van a pie al centro, existe un camino escolar señalizado que llega al colegio desde la Avenida Ciudad de Liria. Su trazado desaparece en ese punto y el recorrido, apenas visible, no se utiliza. En general no existen mecanismos para la seguridad vial en el entorno de los centros educativos y la entrada y salida de los colegios suele estar masificada de coches.

\section{Accesibilidad}

En la actualidad el barrio cuenta con numerosas barreras arquitectónicas, producto de una ocupación masiva de coches en el espacio público, un diseño inadecuado y una excesiva compartimentación de las zonas verdes. De un primer análisis se observa que la zona de las plazas cuenta con muchas barreras arquitectónicas para la accesibilidad: accesos a las viviendas por aceras demasiado estrechas, debido al vallado; intrusión e invasión de los coches, peldaños no adaptados y objetos mal

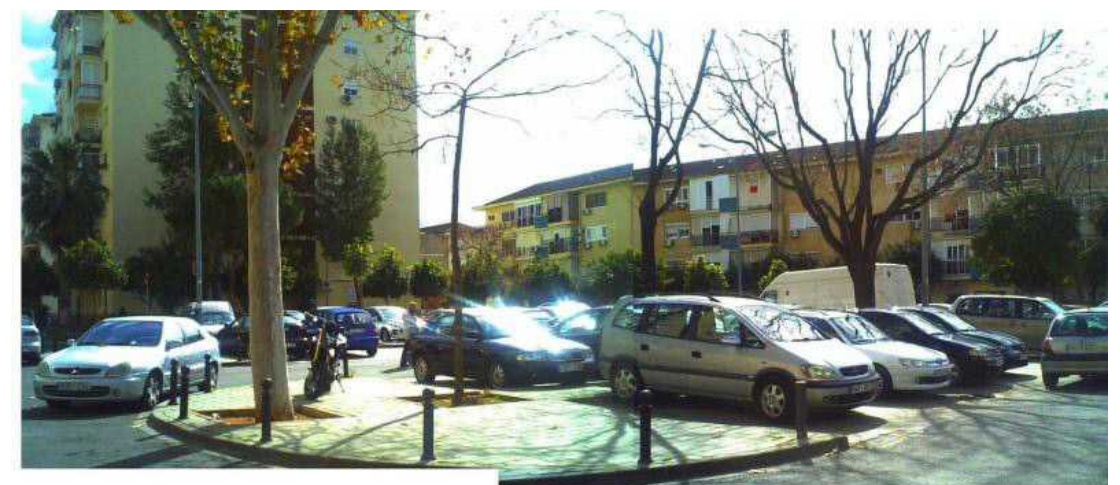
situados (papeleras, árboles, mobiliario urbano, contenedores de basura, postes, etc.). La propia configuración de la plaza permite que la invasión de los coches sea posible, cuentan con un carril de circulación muy ancho que, por un lado, permite la doble fila de aparcamiento, y por otro, permite entrar en la plaza a una velocidad alta. En cuanto al espacio peatonal, el acerado en ángulo recto que delimita la calzada crea espacios inutilizados y resulta insuficiente e inaccesible debido al cercado de las zonas ajardinadas. La calzada es el único elemento continuo en todo el barrio, mientras que los itinerarios peatonales han de sortear todo tipo de obstáculos (fig.13).

La tipología de la edificación, con manzanas cuyos patios están abiertos al paso y la estancia pública, supone una ventaja frente a tipologías con patios de manzana cerrados donde se vuelcan parte de las funciones tradicionales del espacio público. Esta organización posibilita recorridos e itinerarios peatonales a modo de atajos, sin embargo en los frentes de las vías principales como Ciudad de Liria, los pasajes a través de los bajos de los bloques de vivienda están vallados también, por lo que es difícil la orientación en muchos puntos (Fig. 14).

Figura 13. Isla de aparcamientos interior y entrada a una "Plaza" / Vallado de las zonas ajardinadas en la Plaza de Las Monjas. Fuente: elaboración propia. 

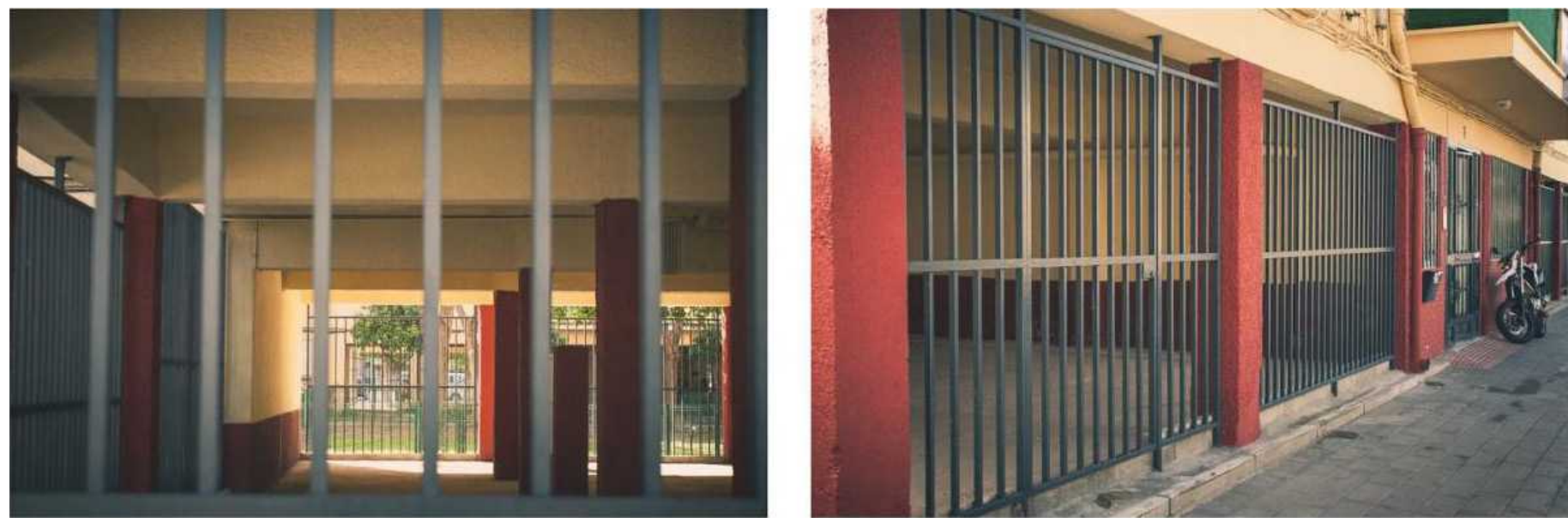

Las avenidas principales que rodean a los grupos de intercomunidades y articulan el barrio poseen varios carriles en cada sentido de un ancho más que suficiente para circular a una velocidad moderada en el interior del ámbito. En la avenida de Chiva nos encontramos con dos carriles en cada sentido, una hilera de aparcamiento en cada lado y espacio suficiente para la "doble fila" (figura 15). Se demuestra que sigue funcionando sin problemas, por lo que una reducción de carriles sería posible.
Figura 14. Soportales de los bloque vallados. Fuente: elaboración propia.
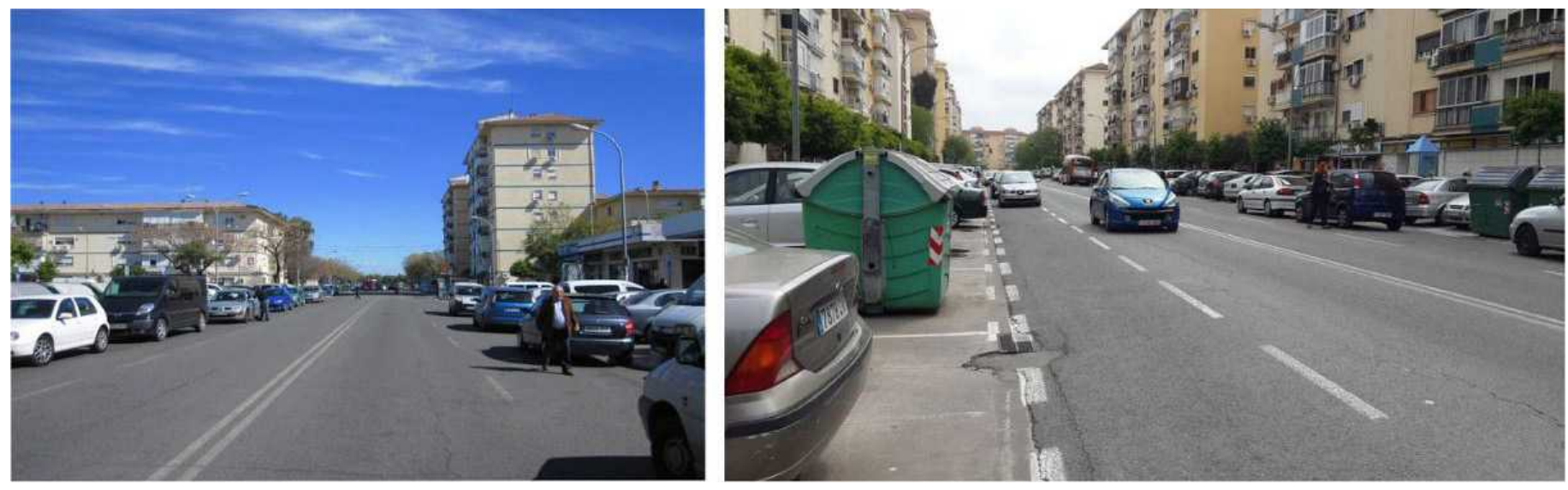

Los cruces para peatones no están bien situados con respecto a los itinerarios cotidianos y en relación a elementos e infraestructuras urbanas como las paradas de bus.

En el resto de vías las problemáticas para los recorridos accesibles universales son similares, a excepción de la avenida de Turia y la de las ONG, que además presentan un desnivel respecto a la calzada en uno de sus lados. Esto genera planos a distinta cota que en muchas ocasiones se salvan mediante tramos de escalera o rampas no adecuadas para
Figura 15. Avenidas de Ciudad de Liria y Ciudad de Chiva. Fuente: Elaboración propia.

Figura 16. Acera elevada y rampas en avenida de las ONG. Fuente: Elaboración propia.
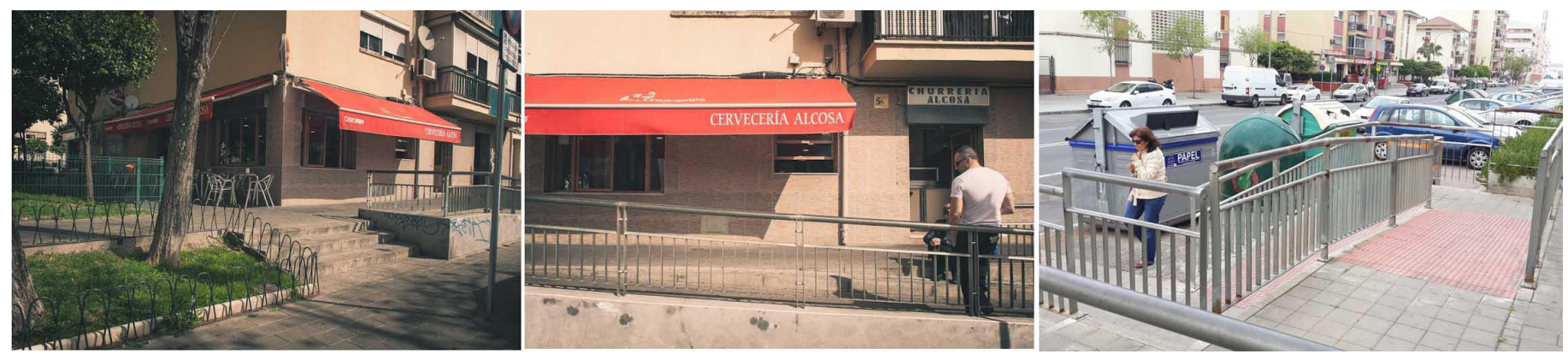

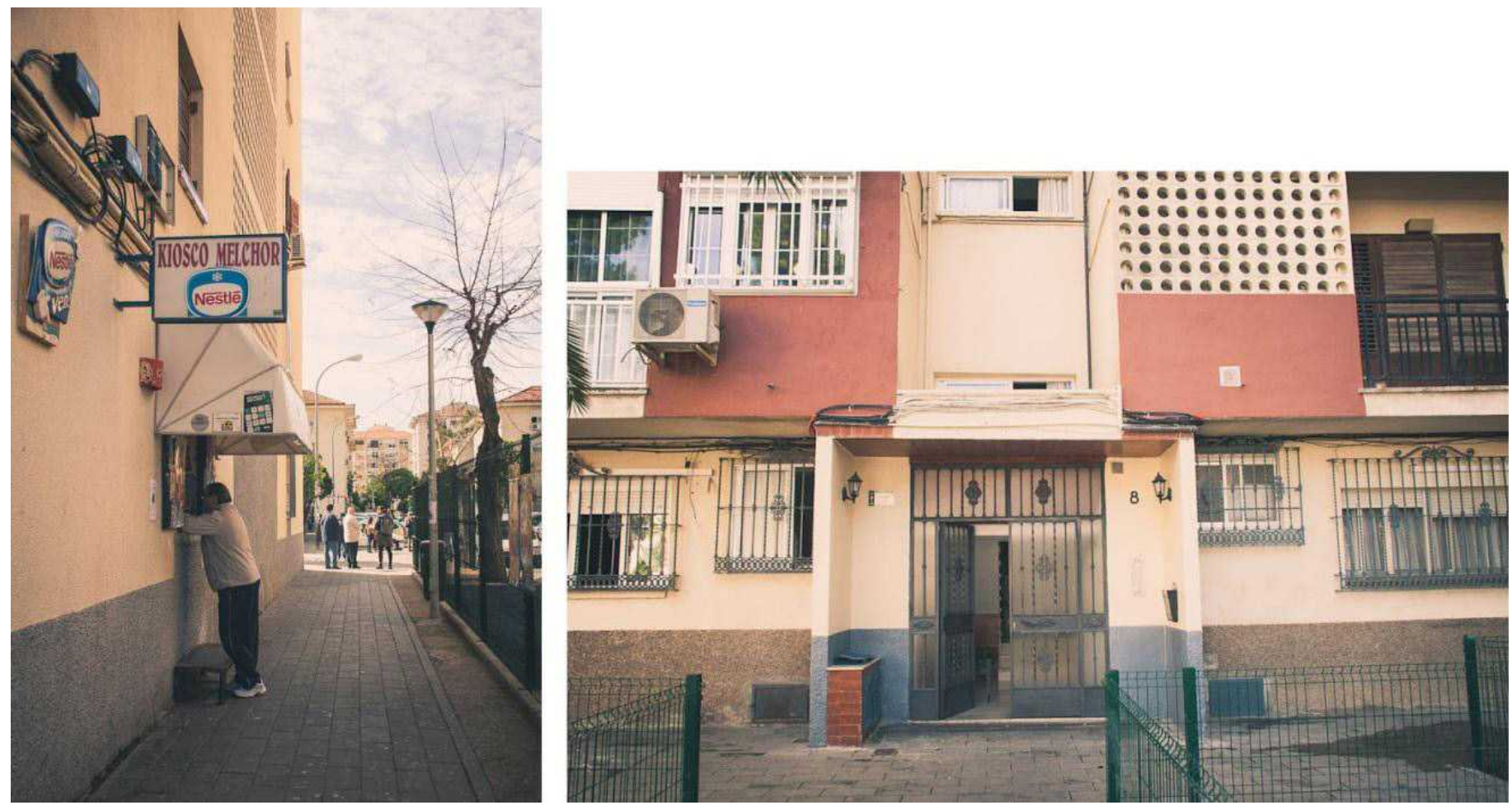

Figura 17. Pasos entre el vallado de las zonas peatonales. Fuente: Elaboración propia. personas con limitaciones de movilidad, población de avanzada edad o con carritos de bebé (Fig.16).

En el interior, en los espacios peatonales vinculados a las viviendas, tanto en las plazas como en los martillos existen barreras arquitectónicas en numerosos puntos. En el trabajo de campo de este estudio se ha podido comprobar alcantarillado mal situado, alcorques deteriorados en mitad del itinerario, problemas para acceder a las viviendas, con escalones, porteros inaccesibles a personas con sillas de ruedas o a niños, y el gran problema, una vez más, del vallado de la zona ajardinada, que deja el espacio para circulación en el perímetro, concentrando el ruido del tránsito debajo de las viviendas y por lo tanto aumentando el conflicto entre lo público y lo privado.

\section{Espacios de relación}

Del sistema de espacios libres y dotaciones locales cabe destacar que el barrio cuenta con una amplia red de espacios ajardinados en muy buen estado. Las plazas y espacios libres están bien distribuidas en el interior del ámbito y el parque del Tamarguillo sitúa al barrio en una posición privilegiada en relación a otros barrios de Sevilla (Fig.18). Aunque esto le otorga una notable calidad ambiental y paisajística, la compartimentación en exceso en el interior y la ocupación de coches, provoca que el porcentaje real de espacios de estancia y relación esté muy por debajo del porcentaje de espacio libre global del que cuenta.

En la tipología de las plazas, los problemas detectados se deben principalmente a la ocupación masiva de coches. Atendiendo al diseño urbano, falta mobiliario y el pavimento y aceras en algunos puntos está deteriorado. Desde el confort y la sociabilidad del espacio, el aspecto que presenta la plaza es más de aparcamiento que dé lugar para relacionarse, las limitadas dimensiones de los recorridos peatonales impiden hacer otra cosa que no sea circular ya que tienen una sección que no admite la incorporación de mobiliario urbano de ningún tipo.

En "Los Martillos", el espacio libre peatonal discurre paralelo a los 


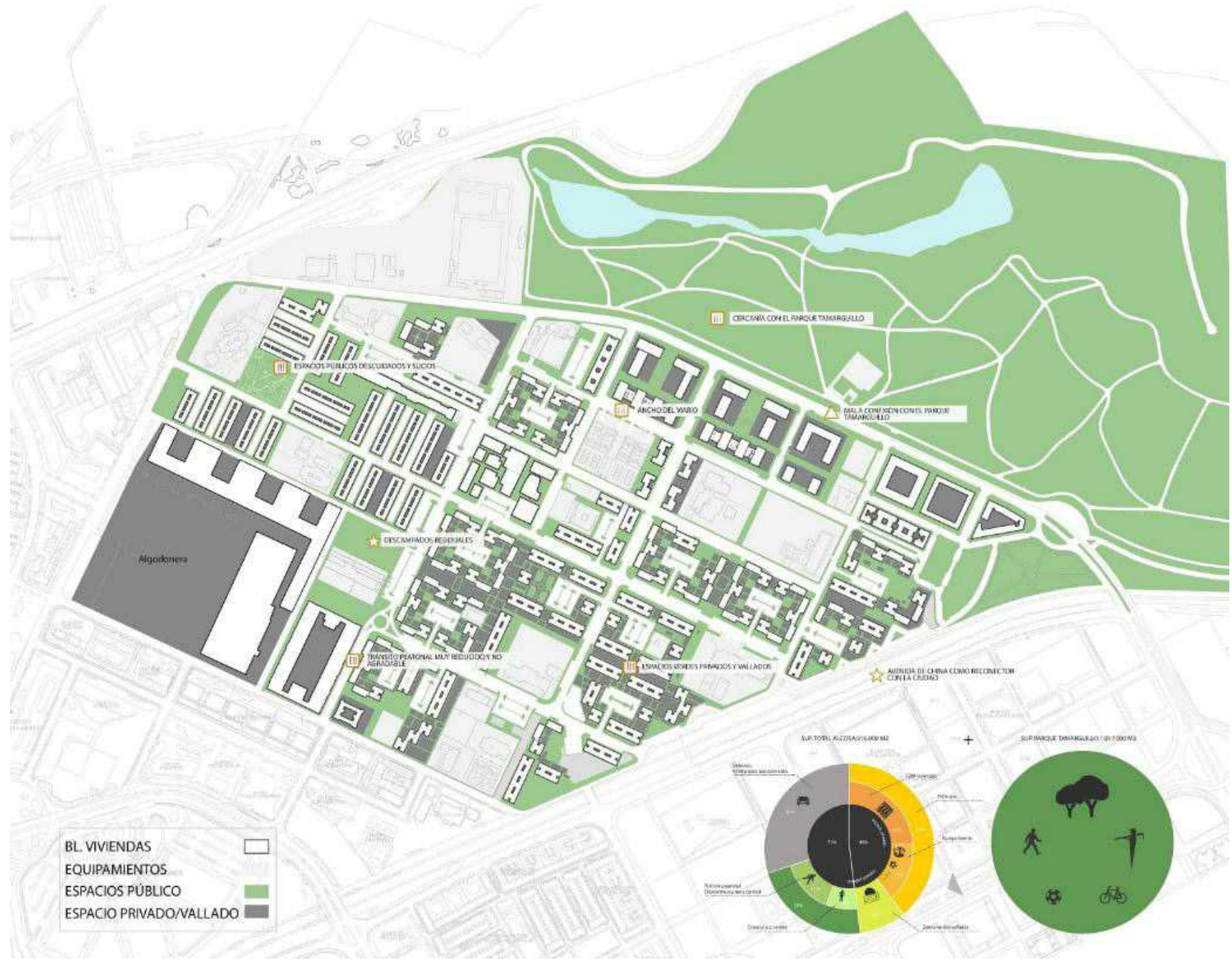

bloques lineales, en la mayoría de los casos está cerrado con vallas. Los que quedan abiertos se utilizan como lugar de paso. No cumplen ninguna función como lugar de relación.

Una aproximación a las intensidades de uso de la red de espacios públicos del barrio que se desprende del trabajo de investigación y diagnóstico, es que el Parque del Tamarguillo es, sin duda, el espacio más intensivo y diverso en perfiles de usuario. Le siguen los comerciales situados en la avenida de Chiva, con calles peatonales a modo de zoco que concentran a mujeres y hombres, también la plaza del padre Castro con el predominio del género masculino, ya que es donde se encuentra la sede de la Asociación de vecinos A. Machado y a la que da la pastilla de comerciales, bares y cafeterías de la zona antigua del barrio. Cerca de allí la plaza Juan García Reyes, el parque de la zona este en la avenida de la República de China usado principalmente por jóvenes y las áreas de juegos infantiles de la Plaza del Obradoiro (figura 19).

Por otro lado, los espacios públicos vinculados a las viviendas son los menos utilizados. El buen mantenimiento ligado a la idea de espacio cerrado y muy regulado impide que se desarrollen relaciones y lugares para el encuentro. No funcionan como espacios comunes debido a conflictos espaciales de tipo generacional, los jóvenes y los niños se ven excluidos de estos espacios por los adultos que han quedado como simples espacios de circulación entre bloques.
Figura 18. Organización y cuantificación espacios libres. Fuente: Álvaro Gomez, Jesus Triviño, Xiao Pujol. Alumnos del Taller de Arquitectura 4.07. profesores: Irene Mendoza, Esteban de Manuel, Marta Donadei, Carlos Díaz-Recasens y Francisco Márquez. 

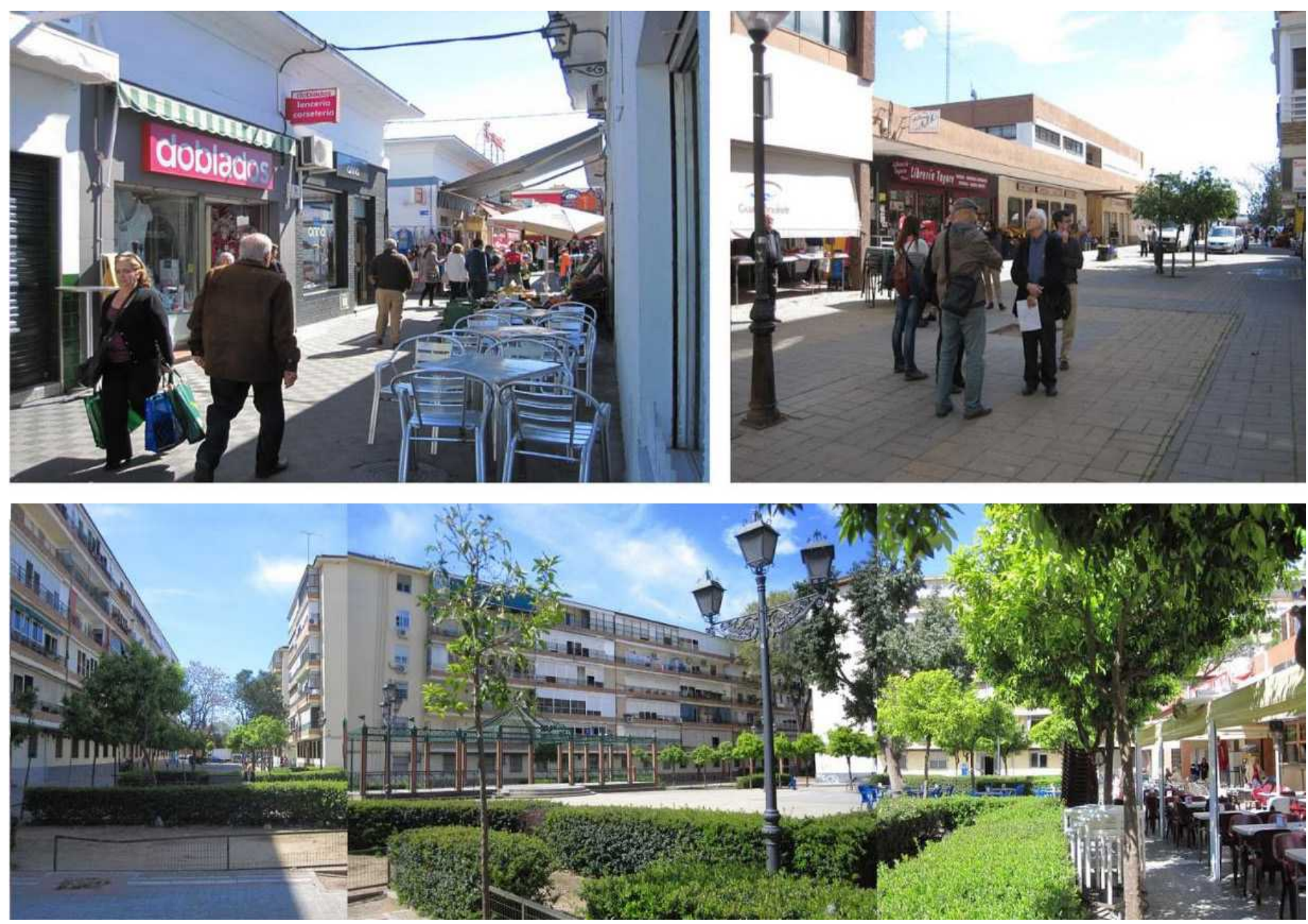

Figura 19. Imagen, de arriba abajo, izquierda a derecha. Comerciales Avda. Ciudad de Chiva, comerciales en Los Martillos, Plaza Padre Castro. Fuente: Elaboración propia

\section{Redes e infraestructuras para la bicicleta}

La bicicleta no es un sistema de transporte muy utilizado para trayectos fuera del barrio, ya que los recorridos son largos hasta el centro y algunos tramos están mal señalizados y resultan dificultosos. Esto ocurre con parte de la línea 5 de carril bici que entra en Santa Clara para enganchar con Kansas City. La red solo entra en el barrio por un punto, la avenida de Turia, desde Alcalde Luis Uruñuela, no existe otro punto de conexión en todo el perímetro del barrio.

La red de carriles bici, aunque pasa por algunas de las principales vías del barrio, no posibilita la conectividad entre las principales zonas donde se realiza la actividad de la vida diaria. En sentido NO-NE, la red discurre por la avenida de Chiva, donde se concentra la actividad comercial y se sitúa el Centro Cívico y el CEIP Arrayanes, pero no continúa más allá de la avenida Ciudad de Liria por lo que la zona antigua del barrio queda excluida de desplazamientos en bici. Otro ramal pasa por la avenida ONG delante de los centros educativos Lope de Rueda y Lope de Vega. De manera transversal a estas vías los carriles bici circulan por la calle Idelfonso Marañón Lavín y avenida Ciudad de Liria, ambos tramos desembocan en el parque, pero desaparecen. La falta de continuidad en la avenida de Séneca dificulta la conexión real entre el corazón del barrio y el parque y por lo tanto este recorrido de la red cotidiana a pesar de la intensa actividad que se desarrolla en él.

Podemos decir que la red es insuficiente desde el punto de vista de los recorridos y actividades diarias que se realizan en el barrio ya que no posibilita acceder a todos los centros educativos, dotaciones 


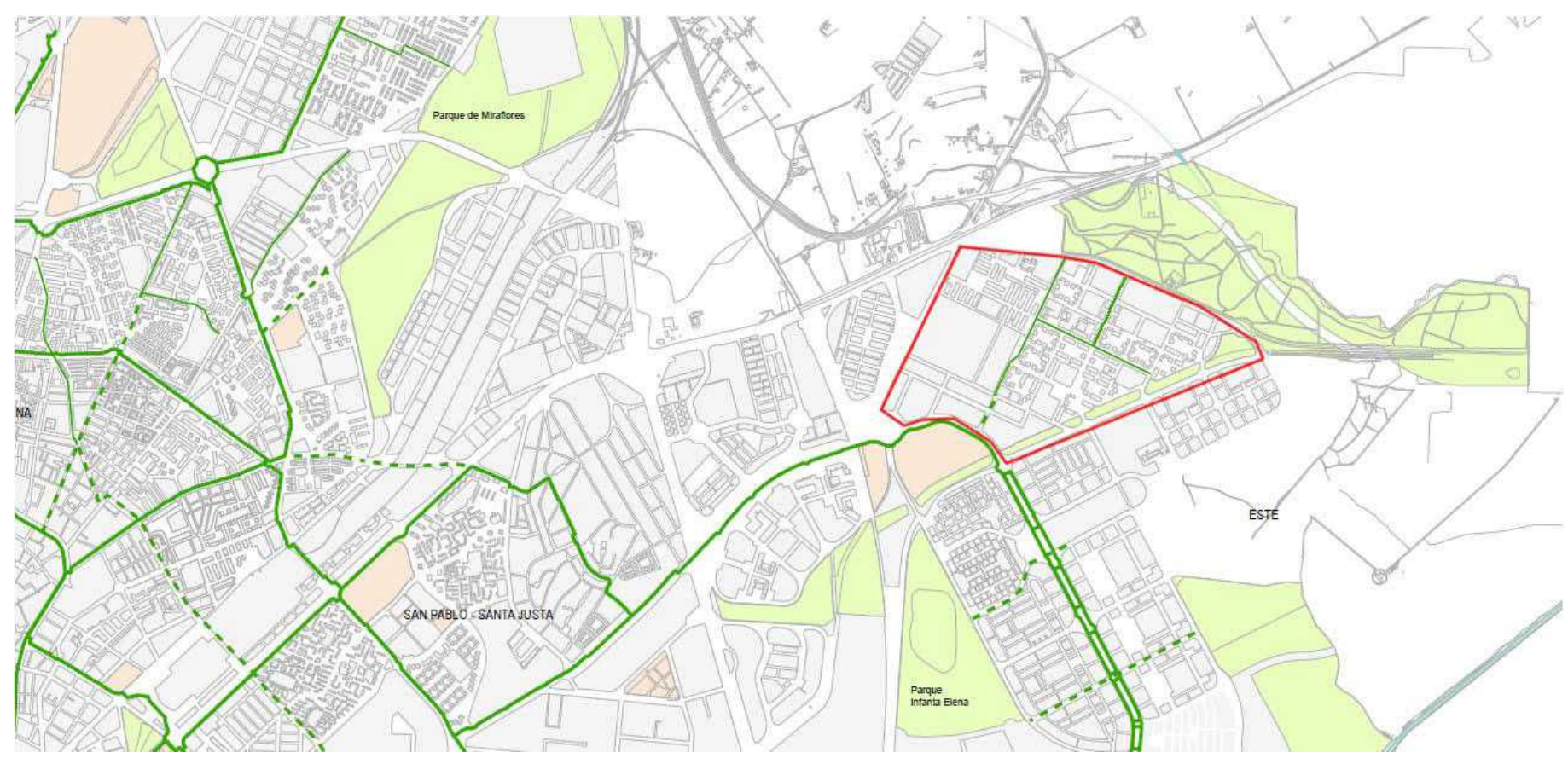

deportivas, áreas comerciales y lugares de identidad barrial. Por otro lado, es interesante destacar la falta de programas de sensibilización y fomento de la bici como medio de transporte.

Respecto a las infraestructuras para la bicicleta, Alcosa cuenta con cinco estaciones de bicicleta pública Sevici, pero carece de bicicleteros y aparcamientos seguros en las zonas comunes de las intercomunidades que posibiliten el fomento de la bici privada.
Figura 20. Red carriles bici en Alcosa. Fuente: elaboración propia a partir del plano de las vías ciclistas de Sevilla. Gerencia de Urbanismo de Sevilla.

Figura 21. Redes de bus y bicicleta en Alcosa. Fuente: Conso González Arriero.

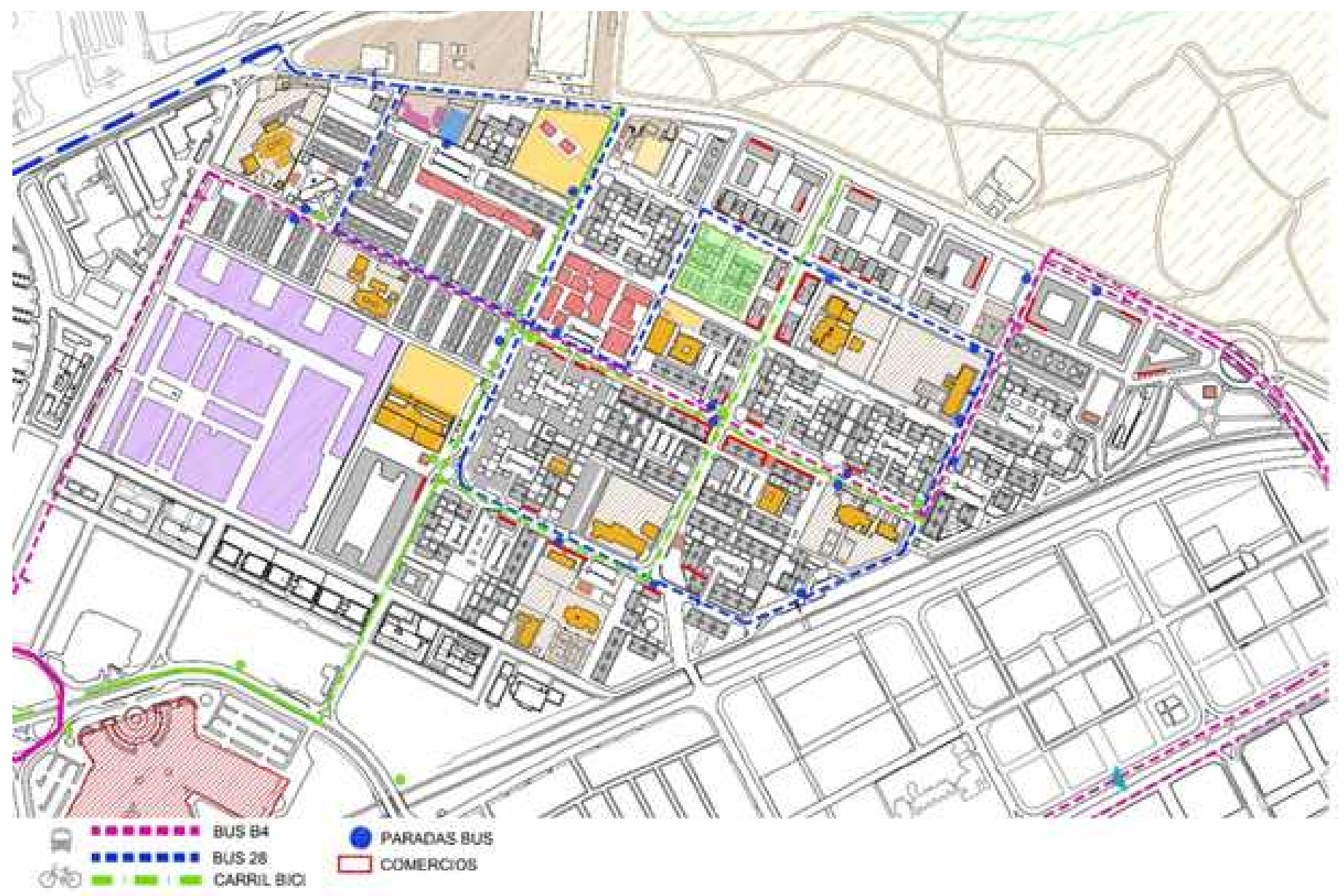




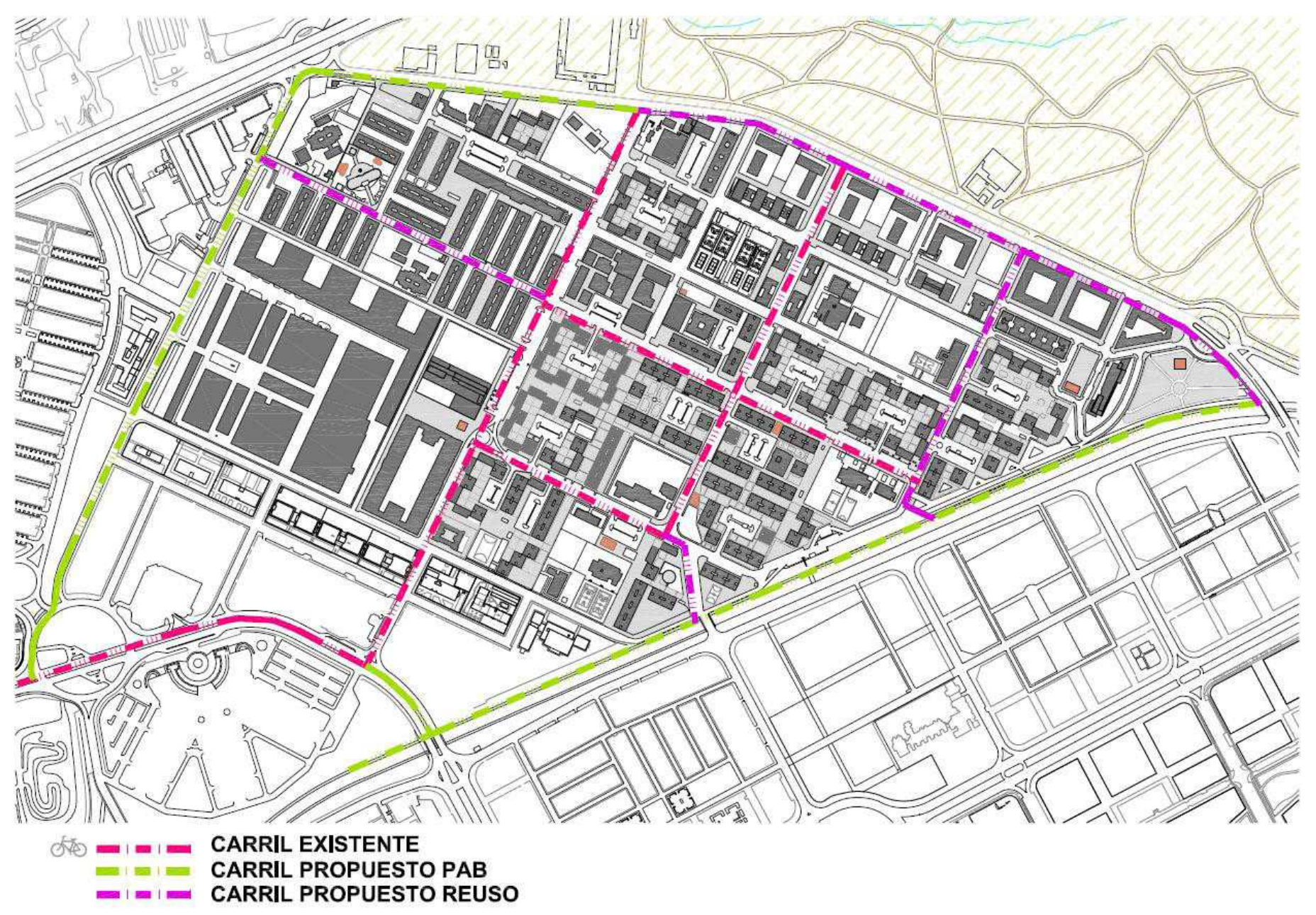

Figura 22. Redes de carriles bici propuestas para Alcosa. Las líneas "REUSO" son las que proponemos como resultado del proyecto Barrios en Transición. Fuente: Conso González Arriero.
Estrategias, objetivos y actuaciones para la mejora del espacio público, la accesibilidad y la movilidad sostenible

La mejora y activación del espacio público requiere la concurrencia de la intervención pública y la participación ciudadana. El objetivo general lo definimos en el proyecto Barrios en Transición como "Mejorar la calidad del espacio urbano de Alcosa, su activación social, económica y cultural”. Los objetivos específicos para conseguirlo son:

a) Potenciación del transporte público, colectivo y de bajo impacto.

b) Garantizar recorridos accesibles para la vida cotidiana en el barrio.

c) Control y ordenación del tráfico.

d) Gestión del aparcamiento para el vehículo privado.

e) Diseñar protocolos para la activación y gestión de usos en el espacio público.

f) Mejorar carencias de diseño y paisaje urbano.

g) Mejorar la calidad ambiental, confort y ahorro energético en los espacios públicos.

h) Generar empleo en el barrio a través de la rehabilitación y regeneración del espacio público.

Cada uno de estos objetivos conlleva el desarrollo de una batería de medidas que contemplan la interacción entre gestión social e intervención sobre el espacio público y la dotación de infraestructuras. Sin un 
cambio de la cultura urbana no habrá reactivación del espacio público ni cambiará la forma de movernos hacia modos activos en combinación con el transporte público. Y viceversa: sin intervenciones sobre el espacio público y sin dotaciones de infraestructuras para la movilidad activa y en transporte público eficiente, no podemos esperar un trasvase suficiente de la movilidad motorizada privada hacia otros modos más sostenibles.

Nos vamos a centrar aquí en el planteamiento de las medidas para mejorar el transporte colectivo y la movilidad activa, tanto en el interior del barrio como en la relación barrio ciudad. La aplicación del concepto de supermanzanas a Alcosa nos permite plantear una reestructuración de las redes de movilidad interior del barrio, favoreciendo el templado del tráfico en las vías articuladoras de barrio y definiendo las áreas de prioridad peatonal. Sobre dicha base planteamos una posible estructura de redes de movilidad activa.

\section{Reorganización del barrio en supermanzanas}

La configuración de Alcosa y su carácter aislado le dan unas condiciones de partida muy favorables para la reorganización de su espacio aplicando el concepto de supermanzanas para incrementar el porcentaje de espacio peatonal. Su viario interior es estructurante del propio barrio y la relación con otros barrios se realiza a través del perimetral, por lo que la presión de vehículos de tránsito es nula.

Las dos vías principales que estructuran el barrio son avenida de Chivas (este-oeste) y perpendicular a ella, Avda. de Turia y su prolongación en calle Ciudad de Liria (norte-sur). En su cruce se encuentra el zoco del barrio. Paralela a Chivas al sur la calle Almendralejo se encuentra a $450 \mathrm{~m}$ en el borde inferior del barrio. Por su parte, $650 \mathrm{~m}$ al este de Liria, la calle Emilia Barral es necesaria para completar las vías estructurantes. Entre ellas se ubica equidistante la Avda. Ildefonso Marañón Lavín que partiría una supermanzana excesivamente grande. Por su parte la Avda. de las ONG, de grandes dimensiones, con dos carriles por sentido, aparece claramente sobredimensionada para la funcionalidad que presta que podría reducirse a permitir el acceso al interior de las "Plazas", para lo cual no precisa tener tránsito de continuidad. Por otra parte está flanqueado por dos colegios del barrio, el Lope de Vega y el Lope de Rueda. El tramo de la calle que atraviesa los colegios podría peatonalizarse sin merma de la funcionalidad de la red viaria para el coche y de este modo se conseguiría una plaza con vocación de espacio relacional significativa. Esta estructura es suficiente para articular la movilidad interior en el barrio con vehículos privados. El resto del viario sería de acceso restringido y velocidad muy reducida, pudiendo compartir plataforma con peatones y ciclistas. De este modo se puede incrementar muy notablemente el porcentaje de espacio público de prioridad peatonal. Las calles actuales dedican el $86 \%$ del espacio al coche. Con esta reorganización se podría reducir a un $25 \%$ dejando el $75 \%$ de prioridad para el peatón (ver figuras 24 y 25).

Esta reestructuración del viario nos va a permitir proponer el desarrollo de las redes verdes peatonales y ciclistas (figura 23-25). 


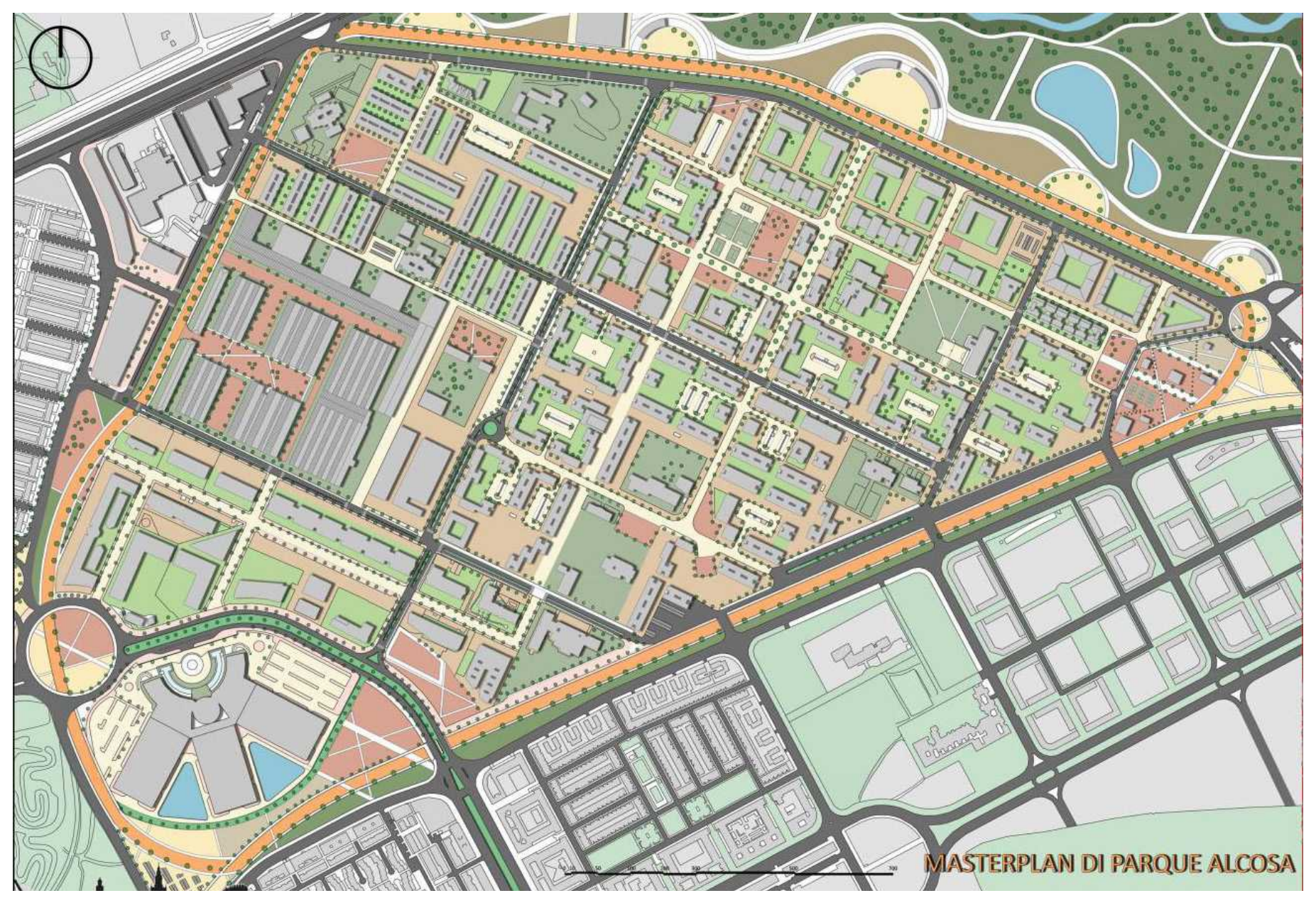

Figura 23. Master Plan de Parque Alcosa. Fuente: elaborado para su tesis de fin de grado por Isabella Selmi en colaboración con el proyecto Barrios en Transición. En gris oscuro aparecen las calles estructurantes del barrio que lo dividen en supermanzanas. El resto es viario de prioridad peatonal. En esta propuesta tanto la Avda. de las ONG como la Avda. Itdefonso Marañón Lavín quedan fuera de la red estructurante.
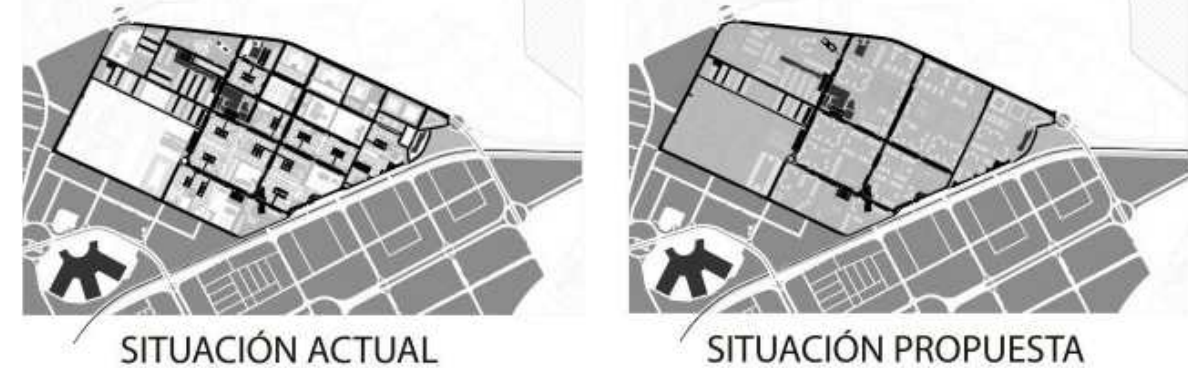

SITUACIÓN PROPUESTA
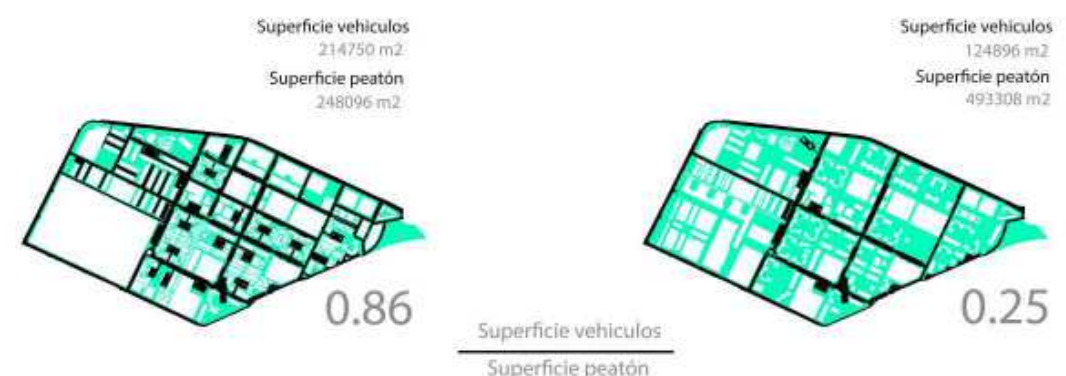

Figura 24. Aplicación del concepto de supermanzanas a Alcosa. Fuente: Planeamiento y Medio Ambiente, curso 2014/15. Trabajo de la asignatura Planeamiento y Medio Ambiente del curso 2014/15. Alumnos: Francisco José Godoy Molina, Aranza del Rocío López, Natalia Pozo Galván, Cristina Quesada Marrón, María Serrano Lavado, Aída Villoria García. Profesores: Antonio Ochoa de Retana, Marta Donadei, Ángel González. En esta propuesta tanto la Avda. de las ONG como la Avda. Ildefonso Marañón Lavín quedan dentro de la red estructurante. 


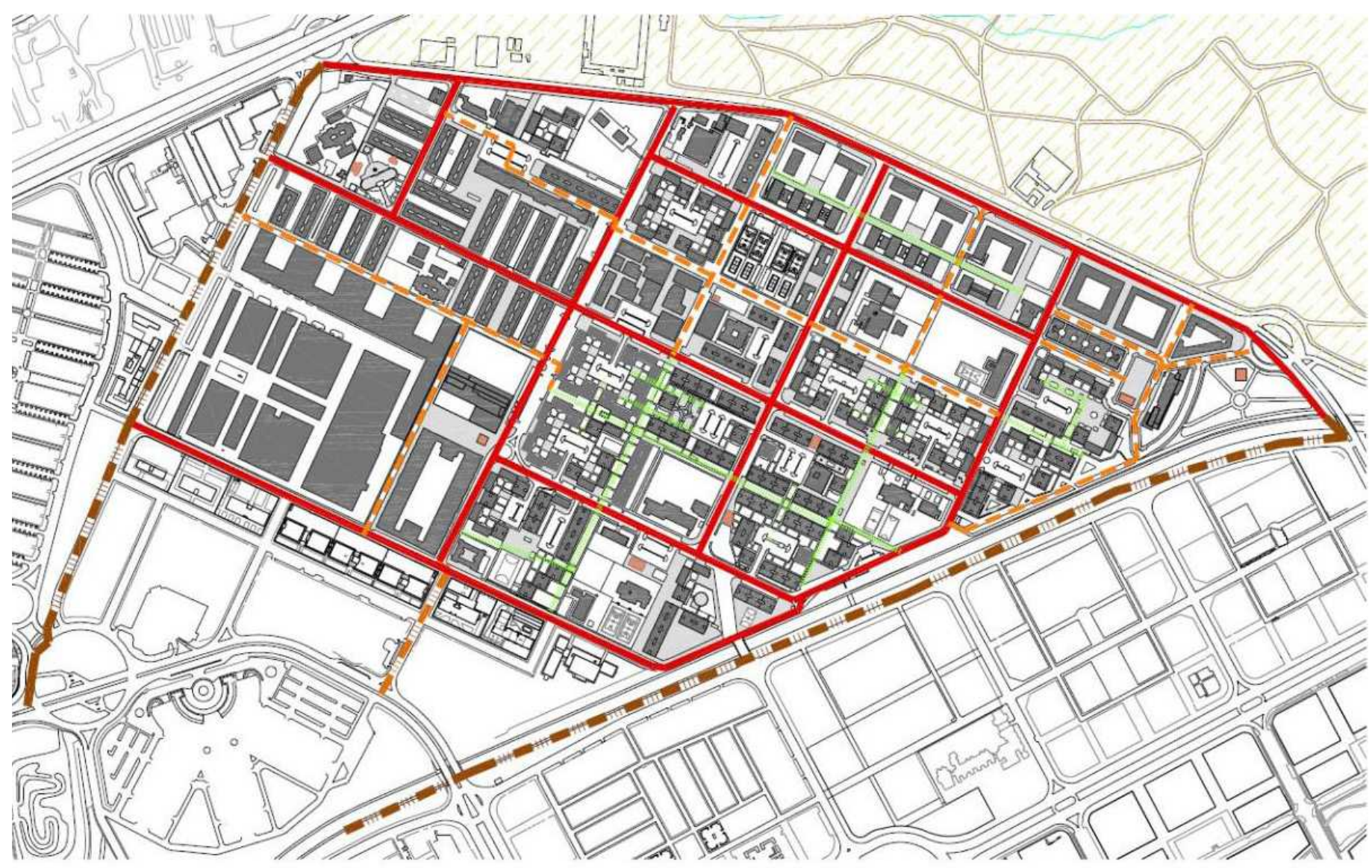

\footnotetext{
ACTUACIONES DE APACIGUAMIENTO DE TRAFICO-ZONA 30KM/h

$="=$ ACTUACIONES DE VIARIOS DE COEXISTENCIA Y PEATONALES. ZONA 20-10 Km/h

ACTUACIONES DE ACCESIBILIDAD UNIVERSAL (Zonas estrictamente peatonales existentes)
}

\section{Potenciación del transporte público, colectivo y de bajo impacto}

Para desarrollar este objetivo proponemos un primer grupo de medidas de sensibilización y educación que necesitan estar acompañadas de otras que mejoren las infraestructuras de movilidad sostenible.

a) Diseñar y realizar campañas de difusión y concienciación

- Jornadas de sensibilización y difusión de los beneficios del transporte público y de bajo impacto como la bici o el caminar con presencia de vecinos del barrio, representantes de área de transporte de Sevilla y de las asociaciones involucradas. Participación en la Semana Europea de la Movilidad.

- Asesoramiento y apoyo para la puesta en práctica del programa de movilidad sostenible en centros educativos. Acompañamiento y asesoría a todos los actores del ámbito educativo, niños, profesores, AMPAS, padres, madres, familiares y vecinos para el diseño de campañas y acciones que conduzcan a una nueva concepción de la educación vial, que amplíe su enfoque más allá de las normas y los reglamentos del tráfico motorizado como los caminos escolares, pedibuses o restricción de coches a la entrada y salida de los colegios del barrio. Incorporación a programas e iniciativas en esta línea como Ciudades que Caminan ${ }^{2}$ y campañas como Mi Cole Camina.
Figura 25. Aplicación del concepto de supermanzanas en Alcosa y actuaciones en el viario. Fuente: Conso González Arriero.
2 http://www.ciudadesquecaminan. org/. 
- Talleres de educación vial, reparación y conducción de bicicletas para adultos y niños.

b) Diseñar y mejorar las infraestructuras para la bicicleta

- Mejorar la Red de itinerarios ciclistas y las infraestructuras asociadas: reparación de los carriles bicis existentes en los puntos donde se requiera. Señalización vertical y horizontal.

- Instalación de aparcamiento de bicicletas seguros para bici privada en dotaciones y centros educativos, así como en los espacios libres comunitarios de los bloques de viviendas. Se colocarán en edificios de equipamientos, con prioridad a los centros educativos, así como en los espacios libres comunitarios de los bloques de viviendas.

- Construcción de intersecciones protegidas: Esta acción se encargará de mejorar los cruces existentes por donde discurre el carril bici: Avenida Ciudad de Chiva-Ciudad de Liria; Avenida Ciudad de Chiva-Ildefonso Marañón Lavín; Las ONG- Ildefonso Marañón; Las ONG-Turia. Con soluciones que contribuyan a aumentar la seguridad de los ciclistas en las intersecciones de carril bici existentes con la calzada.

- Ampliación de la red de carriles bici en el interior del barrio: Se propone el trazado de los carriles bici propuestos en los planes vigentes sin ejecutar y la ampliación en varios puntos que posibiliten un esquema de movilidad ciclista que conecte todo el barrio con la ciudad.

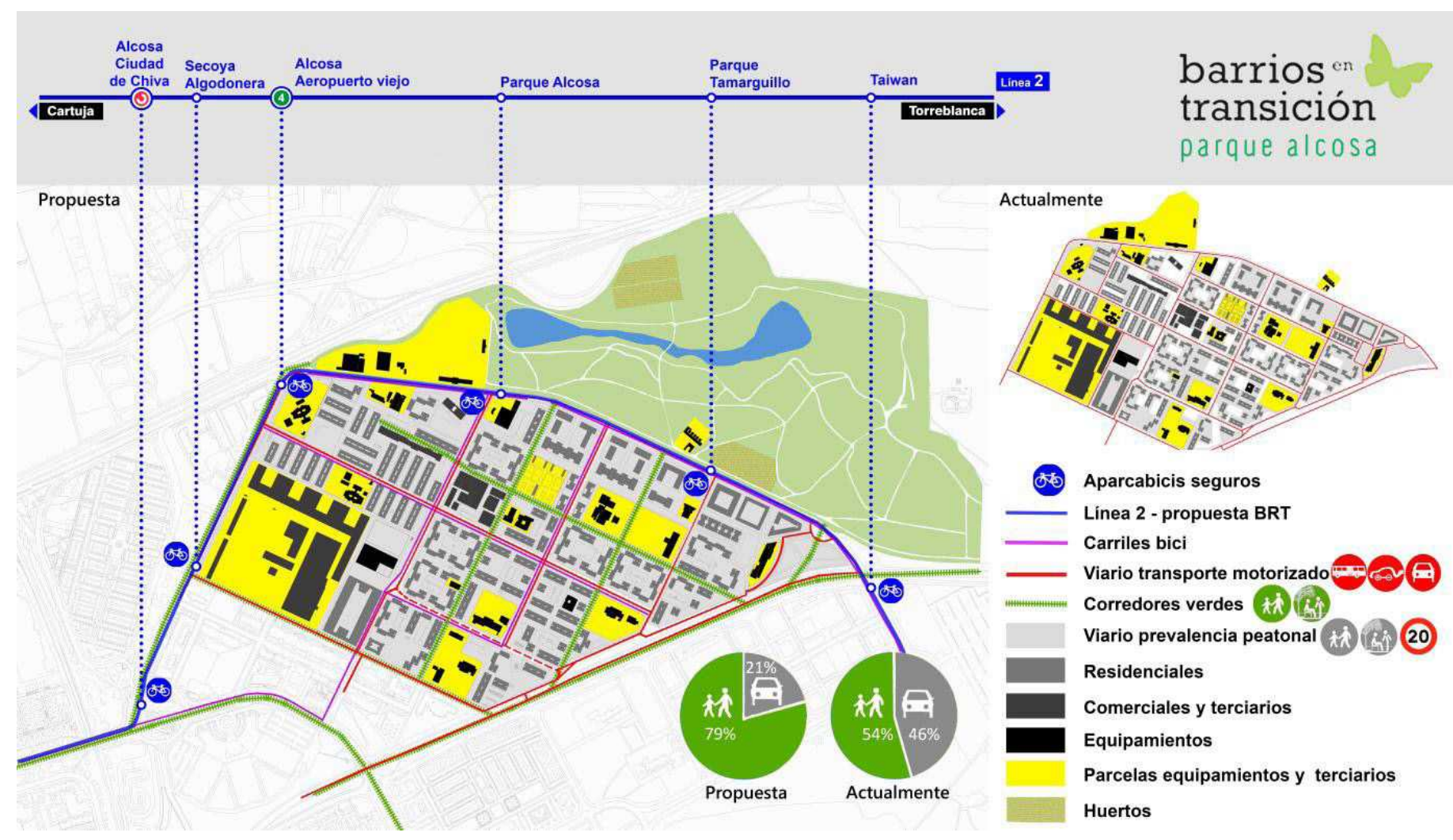

Figura 26. Redes de movilidad sostenible en Alcosa. Fuente: Marta Donadei. c) Fomento del Transporte Público

El fomento del transporte público se producirá a través del rediseño de los recorridos de las tres líneas que dan servicio al barrio y la introducción de medidas para la mejora de frecuencias, la velocidad comer- 
cial y la capacidad de transporte, la renovación de flotas y una buena interconexión entre futuras líneas de metrobús de la ciudad, metro convencional, cercanías, tranvías y autobuses.

- Crear una línea Este-Oeste de BRT: Se propone convertir la línea 27 en línea de alta capacidad y velocidad comercial (BRT) como alternativa a la línea 2 del metro para la conexión del distrito Este con el oeste de la ciudad, introduciendo variaciones en su recorrido.

- Mejorar la velocidad, la frecuencia (4 min) y la funcionalidad de la línea 28 introduciendo plataforma reservada y más vehículos.

- Mejorar la capacidad de articulación del distrito: Se estudiará el recorrido de la línea B4 y su capacidad para alimentar la línea de alta capacidad de BRT y la de cercanías y se incrementará su frecuencia (4 min).

- Otras actuaciones en la Red de transporte público:

a. Introducción del sistema tarifario integrado que unifique los títulos de viaje y tarifas en bus, metro y cercanías.

b. Introduciendo el sistema de picado en las paradas antes de subir al bus.

c. Facilitar la intermodalidad transporte público y bicicleta (tanto pública como privada) siguiendo el modelo europeo de Park\&Ride (aparcamiento bici+bus/tren) o Bike\&Road y Bike on Board (permitir subir la bici al transporte público). Particularmente en la estación Palacio de Congresos.

d. Diseño y ejecución de una red básica de B.R.T.

- Procurar la accesibilidad en las paradas de autobuses, colocándolas al nivel de acceso de los vehículos.

En el trabajo dedicamos una atención especial a diseñar una red básica de BRT como alternativa a la fallida red de metro, paralizada por su insostenibilidad económica. Sin una red de alta capacidad que tenga prestaciones equivalentes a las del metro convencional no se conseguirá que el transporte público gane en atractivo y competitividad frente al coche.

Para el diseño de la Red básica de B.R. T. tomamos en consideración:

- La red de metro prevista para estudiar su sustitución, adaptándola a la red de viario principal de superficie.

- La red de cercanías para procurar la intermodalidad.

- La red de plataformas reservadas de transporte público previstas en el Plan General de Ordenación Urbana.

- El análisis de las líneas principales de autobuses de TUSSAM.

- El análisis de las redes de movilidad del barrio de Alcosa.

La red de B.R. T. está condicionada por la capacidad de la estructura viaria para acogerla y por la propia forma de la trama urbana y los nodos atractores de movilidad (Fig. 27)

El trazado de la línea 2 por el Distrito Este bordea Alcosa por calle Secoya y Avda. Séneca dando servicio al barrio, mejorando la conexión del parque metropolitano del Tamarguillo con la ciudad y dando servicio al Centro Comercial y la ampliación de Sevilla Este. El trazado del B.R.T. permitirá a su vez rediseñar la avenida Séneca y transfor- 


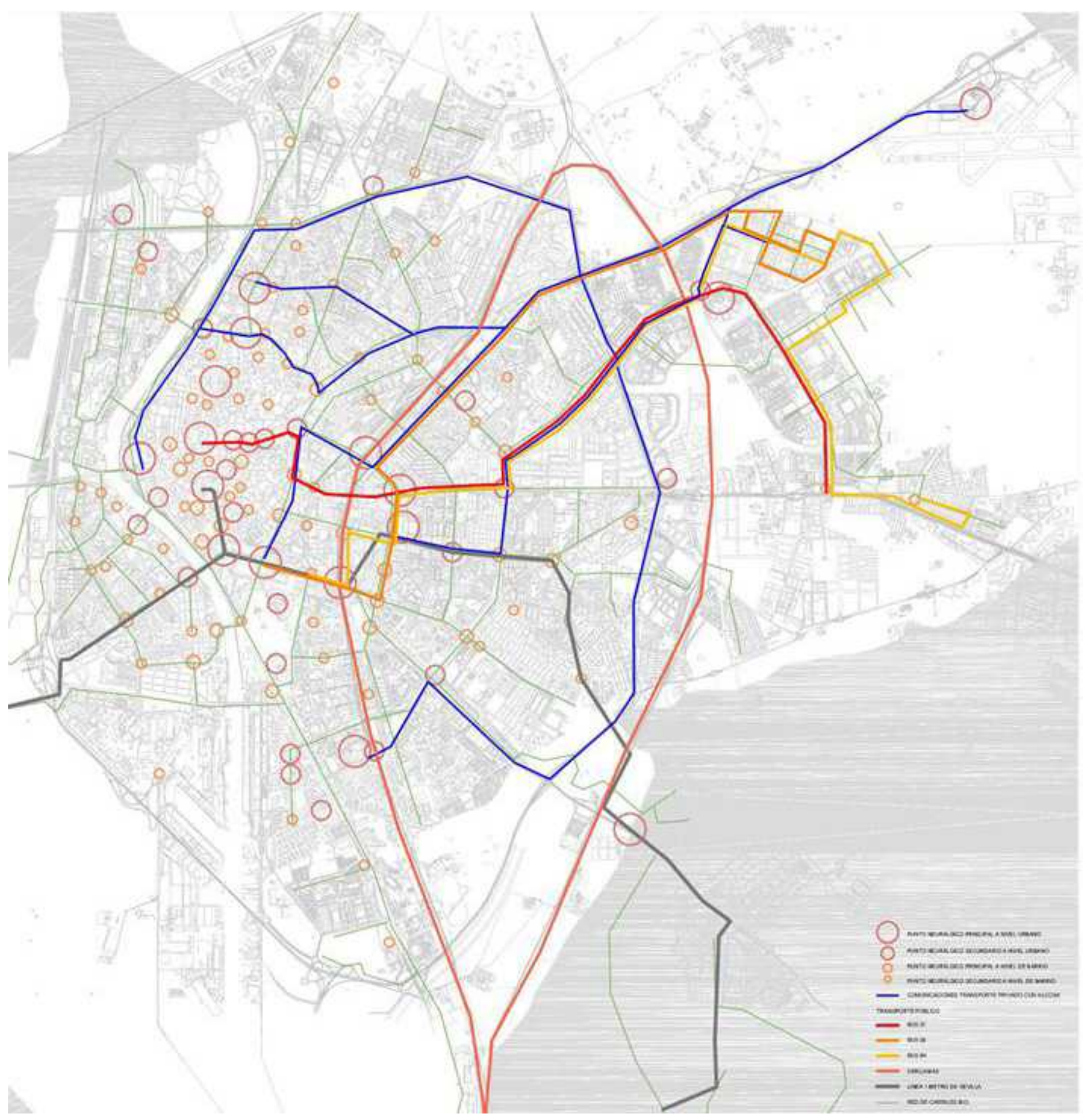

Figura 27. Nodos y redes de transporte público para la relación Alcosa-Sevilla. Fuente: Taller Barrio 4.07, curso 20014/15 en colaboración con Barrios en Transición. Autores: Gómez, Irene; Ricarte, Alberto; Torrejón, Juanjo. Asignatura Taller de Arquitectura 4.07, profesores: Irene Mendoza, Esteban de Manuel, Marta Donadei, Carlos Díaz-Recasens y Francisco Márquez. marla en un bulevar urbano, mejorando la conexión entre Alcosa y el Parque. Por otra parte sería posible hacer un transbordo peatonal en Alcosa entre esta línea y la línea 4, Torre Triana-Aeropuerto (Fig. 28).

La red básica que proponemos incluye dos líneas norte-sur, dos esteoeste y dos circulares.

Esta red básica de B.R.T. que completaría en superficie, sustituyén- 


\section{PROPUESTAS DE MEJORA DE LA MOVILIDAD: Linea 2 BRT}
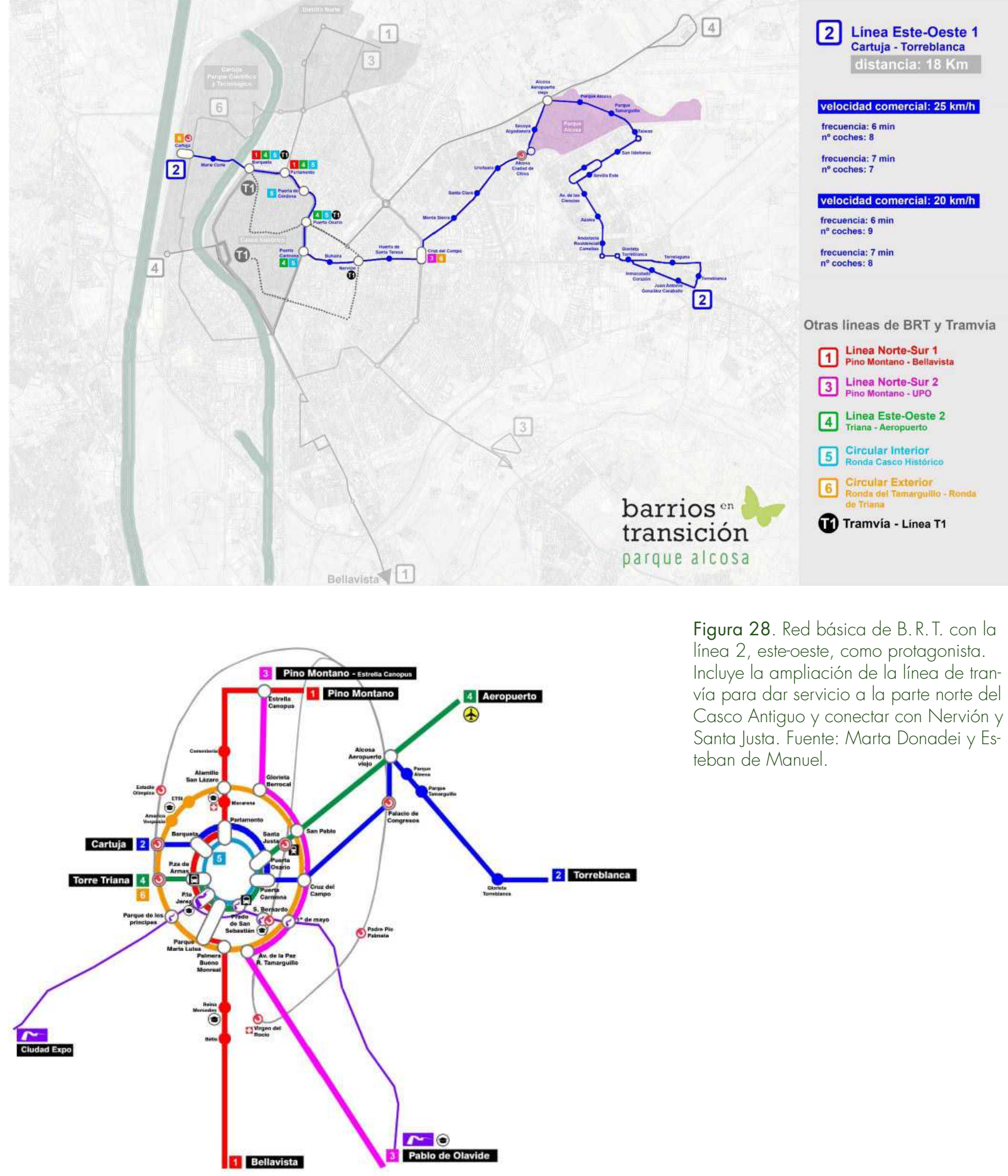

Figura 28. Red básica de B. R. T. con la línea 2, este-oeste, como protagonista. Incluye la ampliación de la línea de tranvía para dar servicio a la parte norte del Casco Antiguo y conectar con Nervión y Santa Justa. Fuente: Marta Donadei y Esteban de Manuel.

Figura 29. Esquema de la Red de Transporte público de Sevilla de alta capacidad compuesta por la línea 1 de metro, la línea circular de cercanías de RENFE y la red básica de B.R.T. propuesta por nuestro equipo. Fuente: Marta Donadei y Esteban de Manuel. 
dolas, las líneas subterráneas no ejecutadas, podría ampliarse en el futuro con líneas que transcurran por el resto de la red de viario principal (Fig. 29). A nivel económico, la reducción de costes de inversión entre la opción metro de superficie y la opción metro subterráneo la reflejamos en el siguiente cuadro.

\begin{tabular}{|l|l|l|l|l|l|}
\hline & \multicolumn{3}{|c|}{ Metro convencional } & \multicolumn{3}{c|}{ Metrobús (BRT) } \\
\hline & Longitud $(\mathrm{km})$ & Coste $($ Mill $€)$ & Coste $/ \mathrm{km}$ & Longitud $(\mathrm{km})$ & Coste $($ Mill $€)$ \\
\hline Línea 2 & 13,4 & 1233 & 92,0 & 13,4 & 93,8 \\
\hline Línea 3 & 11,5 & 1179 & 102,5 & 11,5 & 80,5 \\
\hline Línea 4 & 17,7 & 1090 & 61,6 & 17,7 & 123,9 \\
\hline & & 3502 & & & 298,2 \\
\hline
\end{tabular}

Cuadro 1. Tabla comparativa de costes entre líneas de metro proyectadas y presupuestadas y líneas de BRT propuestas como alternativa. La longitud está medida sobre el trazado en CAD. Tomamos una previsión de costes 7 mill $€ /$ km). Fuente: Elaboración propia.

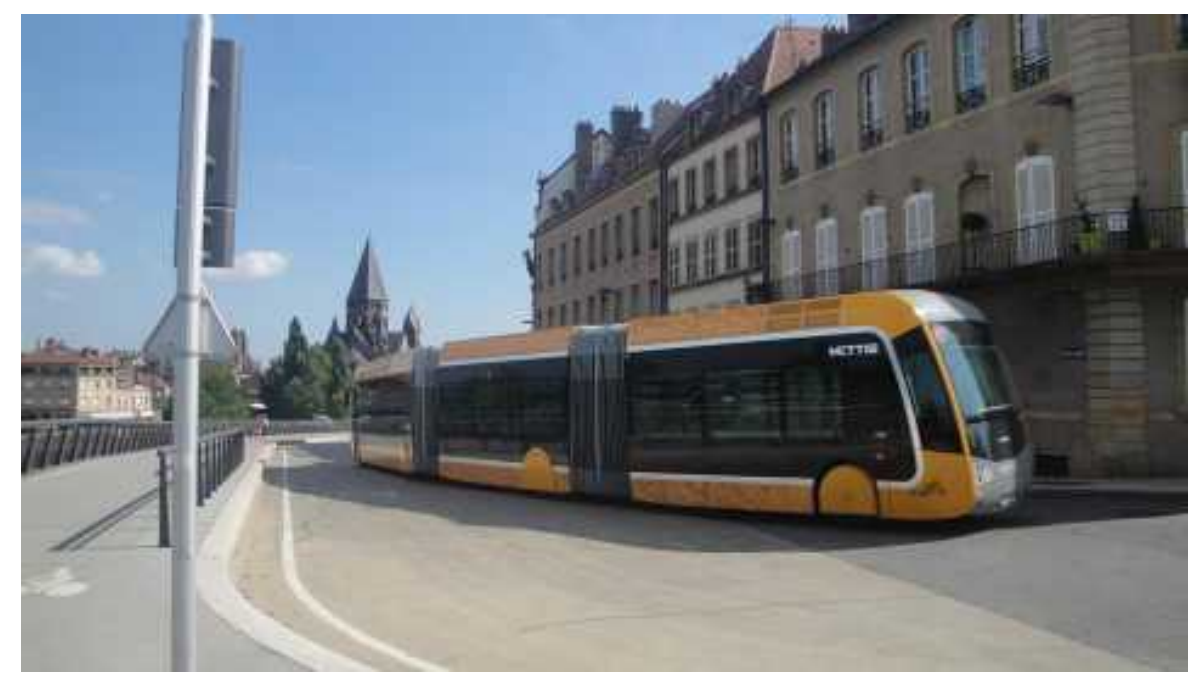

Figura 30. Mettis, Bus de Rápido Tránsito de Metz (Francia) fabricado por Van Hool, modelo Exqui-City. Este vehículo lo ha adquirido también Barcelona y Malmö en versión eléctrica-híbrida (biometano-eléctricos). Fuente: Esteban de Manuel Jerez.

En cuanto a los vehículos existen varias opciones de vehículos de alta capacidad, biarticulados, en función del modo de propulsión (Fig. 30). Nuestro criterio es que dado que la movilidad futura del transporte apunta a la electrificación, habría que estudiar y elegir entre alternativas de transporte electrificadas. Existen varios modelos que se pueden estudiar. Se puede alimentar de forma continua o discontinua. En Málaga se está implantando un vehículo cuyas baterías se recargan mediante inducción dinámica (ENDESA, 2013). El punto débil de estos sistemas son las baterías que encarecen los vehículos y se produce una cierta demora para la carga en las paradas. Parece más aconsejable el sistema de catenaria enterrada, utilizado de forma pionera en la ciudad Coreana de Gumi e implantado con éxito en Nantes, que reduce considerablemente el coste de los vehículos (Vin, 2013). El sistema que 
utilizan se llama OLEV (Online Electric Vehicles) y carga el vehículo de forma inalámbrica por resonancia.

d) Mejora y fomento del sistema de transporte colectivo

- Promoción del viaje compartido en coche y viaje en coche multiusuario. Coordinar e incentivar la creación de plataformas que conecten a los vecinos para que se pongan de acuerdo y empleen un solo automóvil para itinerarios coincidentes. También se incentivará la localización en el barrio de entidades de carsharing, lo que se denomina viaje en coche multiusuario, que es un sistema que ofrece la posibilidad de utilizar un vehículo cuando se necesita sin necesidad de ser propietario.

- Incentivar el Transporte a la demanda. El transporte a la demanda consiste en un sistema de autobuses o microbuses, planificado de forma que el servicio se presta al usuario cuando este ha interactuado con el operador haciéndole llegar sus necesidades de transporte, todo ello a través de métodos telefónicos o telemáticos. Se encuentra especialmente indicado para zonas periféricas como Alcosa donde la demanda se concentra en determinadas franjas horarias.

\section{Garantizar recorridos accesibles para la vida cotidiana en} el barrio

La implantación de la división del barrio en supermanzanas favorece la generación de una red de Itinerarios Accesibles Peatonales que cubra todo el barrio. Para ello es preciso detallar un conjunto de actuaciones.

a) Mejora de la accesibilidad de los itinerarios principales del barrio

Esta actuación se llevaría a cabo a través del trabajo colaborativo de los vecinos para decidir qué itinerarios son prioritarios para solucionar las barreras arquitectónicas y asegurar el cumplimiento de la normativa de accesibilidad.

- Identificación y estudio de itinerarios detallando actuaciones concretas. Se implantarán itinerarios que garanticen la accesibilidad peatonal: Entre todos los portales de los bloques de una plaza, entre plazas, hacia todos los equipamientos del barrio, hacia los locales y zonas comerciales, hacia los espacios públicos (plazas, zonas de juego, etc.), en los bordes del barrio (Avda. de Séneca, Avda. República de China, calle Secoya).

- Mejora de la red de itinerarios peatonales principales. Los elementos de estos viarios deben de reunir un mínimo de requerimientos en cuanto a la accesibilidad universal, anchura, localización y acondicionamiento, para que puedan ser utilizados por todos los habitantes del barrio. ${ }^{3}$ Formarán parte de esta red de itinerarios peatonales elementos del viario urbano como plazas y calle peatonales, aceras de más de 6 metros de anchura en calles templadas o sin circulación intensa, bulevares de más de 8 metros de anchura, calles de coexistencia o intersecciones especialmente acondicionadas. Una vez analizados y seleccionados los pasos para implementar la red de itinerarios peatonales serán:
3 Para cumplir los requerimientos en materia de accesibilidad se basarán en el Decreto 293/2009 de 7 de julio publicado en Boletín Oficial de la Junta de Andalucía el 21 de julio de 2009 'Normas para la accesibilidad en infraestructuras, el urbanismo y el transporte en Andalucía. 
actuaciones de mejora de los niveles de accesibilidad universal en la red principal, continuidad de la red principal, creación de la nueva infraestructura para dar continuidad en aquellos lugares donde no exista y sea impracticable, señalización de los itinerarios principales.

- Ampliación de espacios e itinerarios peatonales y mejora de las áreas estanciales y de convivencia. Mejorar la red de ejes de tránsito peatonal y centros de actividad.

b) Conseguir un cambio de hábitos en la movilidad

Favorecer la movilidad sostenible, a pie o en bicicleta desde el ámbito educativo formal e informal. Diseñar rutas seguras a la escuela involucrando a todos los actores posibles, niños, profesores, padres, AMPAS y vecinos.

- Diseño de Caminos escolares, desarrollando un caso piloto en un colegio del barrio que implique a toda la comunidad educativa, niños, profesores, padres, AMPAS y vecinos, y que pueda ser exportable al resto de centros.

c) Control y ordenación del tráfico

Medidas encaminadas a reducir la intensidad y velocidad de los vehículos que circulan por el barrio

- Poner en marcha programas para la limitación de velocidad. Información y asesoramiento general sobre programas como Ciudades $30 \mathrm{~km} / \mathrm{h}$.

- Apaciguamiento de tráfico, zona 30. Templado del tráfico en las vías principales interiores del barrio para conseguir un espacio público más amable y tranquilo.

- Limitación de la circulación de tráfico en el interior de las supermanzanas. Son áreas de prioridad peatonal, con acceso restringido a residentes, carga y descarga y servicios. Velocidad limitada a 10 $\mathrm{km} / \mathrm{h}$.

d) Gestión del aparcamiento para el vehículo privado

- Reducir el número de vehículos que ocupan el espacio urbano, particularmente en el interior de las plazas, procurando alternativas (Figuras 31 y 32)

- Regular la oferta de aparcamiento para descongestionar el espacio público.

- Estudiar y analizar la ordenación de los lugares habilitados para el estacionamiento en la vía pública en barrio. Se realizará un estudio de demanda, en función de las actividades e infraestructuras generadoras de desplazamientos en vehículo privado, como pueden ser viviendas, comercios, dotaciones o centros deportivos.

- Actuaciones sobre la dotación, localización y tipo de aparcamientos a establecer. Estas actuaciones se harán de forma integrada con el diseño de otras actuaciones de movilidad, teniendo en cuenta la accesibilidad y las expectativas que despierten. 

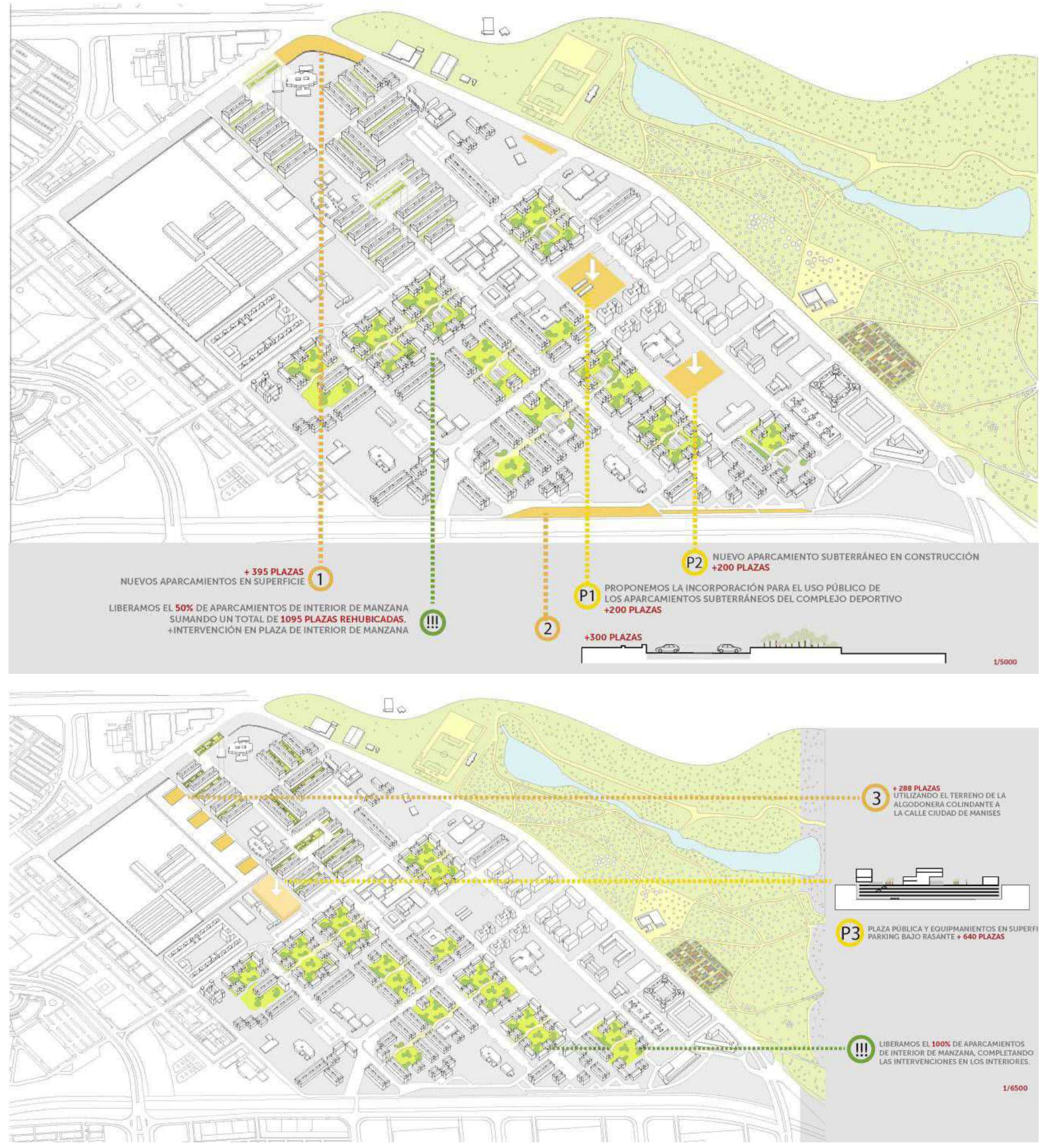

e) Diseñar protocolos para la activación y gestión de usos en el espacio público

Definir nuevos modelos de gestión/cogestión vecinal que sean capaces de impulsar y promover nuevos usos y actividades en el espacio público.

- Analizar las normativas que le afectan a las actividades en el espacio público. Sintetizar las posibilidades y las limitaciones para desarrollar protocolos de usos, horarios o programas en cada espacio.
Figuras 31 y 32. Estudio de reubicación de las plazas de aparcamiento en superficie de "Las Plazas" en dos etapas. Fuente: Trabajo realizado en el Taller 4.07, curso 2014/15 en colaboración con el proyecto Barrios en Transición. Alumnos Xiao Pujol, Jesús Triviño y Álvaro Gómez, profesores Irene Mendoza, Esteban de Manuel, Marta Donadei, Carlos Díaz-Recasens y Francisco Márquez. 
- Identificación de los ámbitos de actuación por colectivos y grupos. Analizar las cualidades de los espacios, dónde están, quién los usa y para qué.

- Definir y poner en marcha una estrategia de gestión participativa en los espacios públicos y privados de uso público del barrio. Estableciendo mecanismos de urbanismo emergente y usos transitorios para establecer actividades y usos.

f) Mejorar carencias de diseño y paisaje urbano

Informar y asesorar de soluciones técnicas que mejoren la accesibilidad y diseño urbano

- Identificación y estudio de las barreras arquitectónicas y deficiencias en el diseño urbano. Trabajo participativo con los vecinos para decidir y priorizar las mejoras que aseguren el cumplimiento de la normativa de accesibilidad. Estudio y seguimiento de los programas de rehabilitación necesarios.

- Desarrollo de casos piloto. Estudio de soluciones y asesoramiento técnico para la eliminación de barreras arquitectónicas, mejora del mobiliario urbano, la accesibilidad universal y el confort.

g) Mejorar la calidad ambiental, confort y ahorro energético en los espacios públicos

Aumentar la eficiencia energética del espacio público:

- Estudio y aplicación de indicadores y medidas para aumentar la calidad ambiental. Los ámbitos de trabajo son dos: buen diseño y tecnologías eficientes.

- Identificación y desarrollo de casos piloto. Asesoramiento en sistemas constructivos para la rehabilitación de un espacio libre mediante la mejora de pavimentos, la vegetación, el control de sombra, fachadas con vegetación, iluminación etc.

h) Generar empleo en el barrio a través de la rehabilitación y regeneración del espacio público

Promover la contratación de empresas constructoras en materia de rehabilitación con cláusulas de inserción laboral. Las empresas contratadas para la rehabilitación del espacio urbano del barrio deberán reservar de un $15 \%$ a un $25 \%$ de los puestos de trabajo que se necesiten para las obras a personas vecinas desempleadas, en riesgo de exclusión, priorizando a los vecinos de los bloques cuyas zonas comunes sean objeto de la rehabilitación.

- Previsión de número de trabajadores. Cuantificación de número de trabajadores potenciales a ser contratados bajo esta modalidad, por fases de ejecución, diferenciando el grado de especialización.

- Orientación y asesoramiento a las comunidades de propietarios en la contratación de las empresas constructoras. Incorporando cláusulas sociales como criterio de valoración en el pliego de condiciones para el contrato de la obra.

- Estudiar y elaborar repertorios de soluciones constructivas y 
tecnológicas adecuadas a las empresas de pequeña escala y el empleo local.

\section{Conclusiones y discusión de resultados}

Los resultados de este trabajo se corresponden con un momento de cierre y devolución dentro de un proceso de Investigación Acción Participativa iniciado en 2012 y concluido en 2015. Han sido presentados en el Centro de Adultos del barrio a los vecinos y vecinas participantes (sesión de presentación y debate realizada el 23-2-2016). Algunas de las medidas aquí propuestas pueden ser desarrolladas de forma autónoma por diferentes actores del barrio. Pero el objetivo que persigue este proceso es provocar el encuentro entre iniciativas top-down con iniciativas bottom-up. Acometer el proceso de transición a la sostenibilidad de un barrio requiere la acción colaborativa y concertada de las administraciones públicas, los vecinos y vecinas (organizados y no organizados), las empresas y de grupos de asistencia técnica interdisciplinares. Es preciso crear espacios de participación y coordinación con capacidad de priorizar acciones y distribuir responsabilidades. Y el rol de los equipos técnicos de acompañamiento al proceso será clave. 


\section{Referencias bibliográficas}

Agencia de Ecología Urbana de Barcelona. (2007). Plan de Movilidad y Espacio Público de Vitoria-Gasteiz | BCNecologia. Recuperado el 20 de febrero de 2016, de: http://www.bcnecologia.net/es/proyectos/plan-de-movilidad-y-espacio-publico-de-vitoriagasteiz.

- (2015). SUPERILLA. La nova cél-lula urbana. Barcelona. Recuperado el 20 de febrero de 2016, de: http://www.bcnecologia.net/sites/default/files/ prensa/bcnecologia_presentacio_superilles.pdf.

Borja, J.; Muxí, Z. (2003). El espacio público, ciudad y ciudadanía. Diputació de Barcelona, Xarxa de Municipis: Electa, Cop., 415.

Calvo Salazar, M. (2013). Movilidad sostenible en nuestras ciudades. Sevilla: Secretariado de Publicaciones, Universidad de Sevilla.

Corral Sáez, C. (2006). Epur si muove: movilidad sostenible para el siglo XXI. It, 75, 40-49.

De Manuel Jerez, E., López Medina, J. M., González Arriero, C., Dimuro, G., Machuca de la Rosa, I., \& Lora Chapela, M. (2012). Barrios en transición. Hábitat Y Sociedad, 5, 35-55. Recuperado el 20 de febrero de 2016, de: http:/ / www.habitatysociedad.us.es.

ENDESA. (2013). Endesa desarrolla en Málaga un sistema para cargar un autobús eléctrico en movimiento y sin cables Endesa.com. Recuperado el 20 de febrero de 2016, de: http:/ /www.endesa.com/ ES/SALADEPRENSA/NOTICIAS/carga-autobuselectrico-induccion-dinamica.

Hérnandez Herrador, V., et al. (2014). Metodología para el desarrollo intermodal bicicleta-transporte público. Área metropolitana de Sevilla. Congreso $\mathrm{Na}$ cional del Medio Ambiente 2014.

José, F. T. (1998). La ciudad y el medio natural. Madrid: Akal.

Junta de Andalucía. (2015). Plan de Transporte Metropolitano del área de Sevilla: Plan de Movilidad Sostenible. Recuperado el 20 de febrero de 2016, de: http:/ / www.juntadeandalucia.es/export/drupaljda/Plan \%20de\%20Transporte \% 20Metropolitano\%20Sevilla\%201.pdf.

Lerner, J. (2003). Acupuntura Urbana. Rio de JaneiroSao Paulo: Editora Record.
Llop, C, y Rueda, S. (2011). ¿Nuevos barrios urbanos o nuevos ecodistritos? Regeneración urbana vs. extensión. La propuesta de ecodistrito para Alcobendas como proyecto-posición para un urbanismo renovado. Urban e.

López Medina, J. M. (2010). Metodologias participativas para la gestión del hábitat. Hábitat Y Sociedad, 1, 83-103. Recuperado el 20 de febrero de 2016, de: http:/ / www.habitatysociedad.us.es.

Mollinedo, C. L. (2006). Movilidad urbana sostenible: un reto para las ciudades del siglo XXI. Economía, Sociedad Y Territorio, VI, 1-35.

Morales, E. et al. (2014). Diagnóstico participativo del barrio: Taller Plan Base-Plan Barrio para el Parque Alcosa. Recuperado el 20 de febrero de 2016 de: http:/ / www.laciudadviva.org/blogs /?p=23135.

Peters, P. (1979). La ciudad peatonal. Barcelona: Gustavo Gili.

Rueda, S. y Soler Trillo, J. (codirectores) (2004). Bases per a la implantació d'una nova xarxa de BUS per Barcelona en el marc d'un nou model de mobilitat. Recuperado el 20 de febrero de 2016 de: http:/ / www.bcnecologia.net/.

United Cities and Local Governments. (2010). Friburgo. Alemania. Ecobarrio de Vauban. Recuperado el 20 de febrero de 2016 de: http://www.uclg-cisdp.org/sites/default/files/Friburgo_2010_es_FINAL_0.pdf.

Verdaguer, C. (2000). De la sostenibilidad a los ecobarrios. Documentación Social, 119, 59-78. Recuperado el 20 de febrero de 2016 de: http:/ / oa.upm. es/5827/1/De_la_sostenibilidad_a_los_ecobarrios. pdf.

Vin, N. (2013). Corea del Sur estableció autobús $100 \%$ eléctrico que se carga a través del aire de forma inalámbrica. Recuperado el 20 de febrero de 2016 de: http:/ / ultimasnoticiasnew.blogspot.com. es/2013/08/corea-del-sur-establecio-autobus-100. html. 
MANUEL JEREZ, Esteban, Conso GONZÁLEZ ARRIERO y Marta DONADEI. Las redes de Movilidad Urbana Sostenible y la reactivación del Espacio Público: Alcosa. Hábitat y Sociedad, 2016, n. ${ }^{\circ}$ 9, pp. 97-131. $<w w w . h a b i t a t y s o c i e d a d . u s . e s>$

http://dx.doi.org/10.12795/HabitatySociedad.2016.i9.06 $\bigcirc$ 